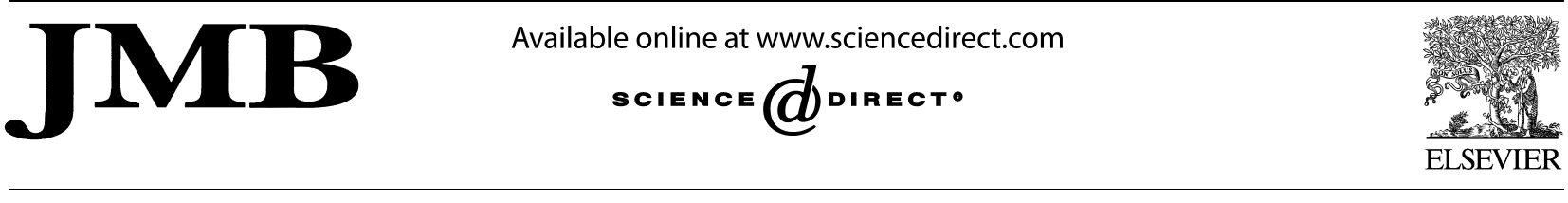

\title{
The Influence of a Transmembrane pH Gradient on Protonation Probabilities of Bacteriorhodopsin: The Structural Basis of the Back-Pressure Effect
}

\author{
Nicolas Calimet ${ }^{1}$ and G. Matthias UlImann ${ }^{1,2 *}$
}

${ }^{1}$ IWR-Computational

Molecular Biophysics

University of Heidelberg, Im

Neuenheimer Feld 368, 69120

Heidelberg, Germany

${ }^{2}$ Structural

Biology/Bioinformatics

University of Bayreuth

Universitätsstr. 30, BGI, 95447

Bayreuth, Germany

\begin{abstract}
Bacteriorhodopsin pumps protons across a membrane using the energy of light. The proton pumping is inhibited when the transmembrane proton gradient that the protein generates becomes larger than four $\mathrm{pH}$ units. This phenomenon is known as the back-pressure effect. Here, we investigate the structural basis of this effect by predicting the influence of a transmembrane $\mathrm{pH}$ gradient on the titration behavior of bacteriorhodopsin. For this purpose we introduce a method that accounts for a $\mathrm{pH}$ gradient in protonation probability calculations. The method considers that in a transmembrane protein, which is exposed to two different aqueous phases, each titratable residue is accessible for protons from one side of the membrane depending on its hydrogen-bond pattern. This method is applied to several ground-state structures of bacteriorhodopsin, which residues already present complicated titration behaviors in the absence of a proton gradient. Our calculations show that a $\mathrm{pH}$ gradient across the membrane influences in a non-trivial manner the protonation probabilities of six titratable residues which are known to participate in the proton transfer: D85, D96, D115, E194, E204, and the Schiff base. The residues connected to one side of the membrane are influenced by the $\mathrm{pH}$ on the other side because of their long-range electrostatic interactions within the protein. In particular, D115 senses the $\mathrm{pH}$ at the cytoplasmic side of the membrane and transmits this information to D85 and the Schiff base. We propose that the strong electrostatic interactions found between D85, D115, and the Schiff base as well as the interplay of their respective protonation states under the influence of a transmembrane $\mathrm{pH}$ gradient are responsible for the back-pressure effect on bacteriorhodopsin.
\end{abstract}

(c) 2004 Elsevier Ltd. All rights reserved.

Keywords: titration calculations; continuum electrostatics; transmembrane protein; $\mathrm{pH}$ gradient; irregular titrations branes in chloroplasts or mitochondria, where a $\mathrm{pH}$ gradient of about one to four $\mathrm{pH}$ units can be generated over the membrane and converted to other forms of energy via a passive back-diffusion of the proton through specialized transmembrane proteins $\left(\mathrm{H}^{+}\right.$-ATP-Synthase, proton-motor). In many of these systems, the electrochemical gradient is generated by transmembrane proteins, which actively pump protons across the membrane. This active transfer requires an external source of energy, such as light or chemical energy.

An important question regarding proton pumps arises from the apparent antagonism of their transport function and the electrochemical gradient that they produce. As $\Delta \mathrm{pH}$ increases, the work associated with the active transfer of a proton across the

Abbreviations used: BR, bacteriorhodopsin; SB, Schiff base; MC, Monte Carlo.

E-mail address of the corresponding author: matthias.ullmann@uni-bayreuth.de 
membrane increases proportionally. The generated membrane potential difference also adds to this work. Indeed, the electrochemical gradient generated by a proton pump has been observed to affect profoundly the pumping rate of the protein, a phenomenon commonly referred to as the backpressure effect of the electrochemical gradient. ${ }^{1,2}$ In other words, the proton pump is inhibited by the electrochemical gradient that it generates, implying that there is a maximally attainable $\mathrm{pH}$ gradient. The back-pressure effect and large but finite $\mathrm{pH}$ gradients have been confirmed experimentally in various conditions. ${ }^{3-10}$ Therefore, accounting for the effect of the transmembrane $\mathrm{pH}$ gradient on the protein is expected to help elucidating how proton pumps function.

Numerous experimental studies of proton pumps exist in the literature. To date, the most extensively characterized proton pump is bacteriorhodopsin (BR), which is also one of the simplest pumps found in nature. BR uses the light energy to transfer a proton from the cytoplasm of Halobacterium salinarum to the extracellular space. The generated proton gradient is then consumed by ATP-synthase to synthetize ATP from ADP and inorganic phosphate. Upon light illumination, BR undergoes a series of conformational changes (the photocycle), which results in the successive modifications of the proton affinity of its internal polar residues. The changes in proton affinities along the photocycle are responsible for the transfer of one proton across the membrane. Even though a lot of structural and biochemical information is available for BR, the details of its function are still not fully understood at the atomic level. Most of the experimental titrations and kinetics of BR have been performed with the protein embedded in its natural lipid environment (called the purple membrane) and in various conditions of acidity, humidity, temperature, pressure and salt concentrations. ${ }^{11-15}$ The purple membrane is usually prepared in the form of thin films, which are not adequate to study the effect of a $\mathrm{pH}$ gradient on the protein. Moreover, such gradients are often unwanted because they complicate the analysis of the titration experiments. Therefore, ionophores or other substances are usually added to reduce or consume the $\mathrm{pH}$ gradient. On the other hand, various kinds of experiments have been conducted on liposomes, ${ }^{7,16-21}$ or whole cells $^{22,23}$ containing BR proteins. Such conditions allow, in principle, study of the back-pressure effect of the $\mathrm{pH}$ gradient on BR. However, no individual titration experiments have been performed on BR embedded in membrane vesicles. Theoretical studies can help to understand the titration behavior of the protein under the influence of a transmembrane $\mathrm{pH}$ gradient, which is present under physiological conditions.

Here, we investigate the influence of a transmembrane $\mathrm{pH}$ gradient on the titration behavior of BR. We relate our calculations to experiments in which the effect of a transmembrane $\mathrm{pH}$ gradient was considered. For this purpose, an existing formalism of calculating protonation probabilities as a function of a single $\mathrm{pH}^{24-26}$ is extended to account for different $\mathrm{pH}$ values at the two sides of a membrane. This extension is valid for any transmembrane protein and is not restricted to BR only. The $\mathrm{pH}$ titration of BR has been already investigated theoretically by continuum electrostatic calculations, ${ }^{27-35}$ which lead to an excellent agreement with experimental data. However, none of these theoretical studies considered the effect of a transmembrane $\mathrm{pH}$ gradient. This work represents to the best of our knowledge the first theoretical study on the influence of a transmembrane $\mathrm{pH}$ gradient on the titration behavior of a transmembrane protein.

In the first part, we summarize the existing titration method and introduce an extension of this method to account for a $\mathrm{pH}$ difference between two reservoirs of protons separated by a membrane. In the second part, we analyze and discuss the results obtained by applying this method to $B R$, in which functional residues face different solvent and membrane environments. The accessibility of the titratable sites for protons from the extracellular or the cytoplasmic solvent is determined from the hydrogen bond network that involves polar side-chains, internal cavities, and solvent-accessible residues of the protein. We discuss the importance of the long-range electrostatic interactions between distant titratable residues. These interactions are responsible for the effect of the transmembrane $\mathrm{pH}$ gradient. We analyze the two-dimensional titration curves calculated as a function of the $\mathrm{pH}$ in the extracellular space and the $\mathrm{pH}$ in the cytoplasm. Based on our calculations, we propose that the electrostatic interactions between D115, D85, and the Schiff base as well as the interplay of their protonation states are responsible for the back-pressure effect observed for BR.

\section{Theory \\ Titration calculations in proteins}

Theoretical calculations of the protonation probability of the titratable sites in a protein are usually based on continuum electrostatics models. ${ }^{25,26}$ Such models treat the protein as a low dielectric region in a high dielectric medium which represents the solvent. Atoms are modeled as spatially fixed partial atomic charges embedded in the low dielectric region. Mobile ions in solution are represented as a Boltzmann-distributed charge density. The electrostatic potential and the electrostatic energy of such a system can be obtained from the solution of the Poisson-Boltzmann equation.

The titration of a single protonatable site is determined by its $\mathrm{p} K_{\mathrm{a}}$ value. In a protein, the $\mathrm{p} K_{\mathrm{a}}$ value of a protonatable site can be shifted compared to the $\mathrm{p} K_{\mathrm{a}}$ value of the same site in aqueous solution. ${ }^{24}$ This shift is caused by two effects. First, 
the site interacts with several charged and dipolar groups within the protein which can stabilize or destabilize the charged form. Second, the larger low-dielectric volume of the protein in which the site is embedded decreases the solvent reaction field. The second effect destabilizes the charged form when the site is buried in the protein.

While the titration curves of single protonatable sites show a sigmoidal behavior, the titration curves can become irregular in molecules with many interacting protonatable sites. ${ }^{36-39}$ This effect is due to the interactions between protonatable sites that titrate in the same $\mathrm{pH}$ range. A protein with $N$ titratable sites has $2^{N}$ different protonation states if each protonatable site has two forms, protonated or not. The protonation state $n$ of the protein is defined by a protonation state vector $\vec{x}^{n}=\left\{x_{1}^{n}, x_{2}^{n}, \ldots x_{N}^{n}\right\}$. The component $x_{i}^{n}$ of this vector is either 1 or 0 , depending on whether site $i$ is protonated or not. The energy $G_{n}$ of the protonation state $n$ of a protein is given by equation (1):

$$
\begin{aligned}
G_{n}(\mathrm{pH})= & \sum_{i=1}^{N}\left(\left(x_{i}^{n}-x_{i}^{\mathrm{o}}\right) R T \ln 10\left(\mathrm{pH}-\mathrm{p} K_{\mathrm{a}, i}^{\mathrm{intr}}\right)\right) \\
& +\frac{1}{2} \sum_{i=1}^{N} \sum_{j=1}^{N}\left(W_{i j}\left(x_{i}^{n}-x_{i}^{o}\right)\left(x_{j}^{n}-x_{j}^{\mathrm{o}}\right)\right)
\end{aligned}
$$

where $x_{i}^{\mathrm{o}}$ is the reference state protonation of site $i$. We consider the totally uncharged state as reference state. $R$ is the universal gas constant and $T$ the absolute temperature. Equation (1) assumes that the contributions to the energy $G_{n}$ are purely additive, which is valid when the linearized Poisson-Boltzmann equation is applied. The intrinsic $\mathrm{p} K_{\mathrm{a}}$ value $\left(\mathrm{p} K_{\mathrm{a}, i}^{\mathrm{intr}}\right)$ is the $\mathrm{p} K_{\mathrm{a}}$ value that the site $i$ would have if all the other titratable sites would be in their reference protonation form. The $W_{i j}$ term is the interaction energy between sites $i$ and $j$ when they are in their charged forms. Explicit expressions for the individual terms are given elsewhere. ${ }^{24,26,40}$ The energy of each state depends on the $\mathrm{pH}$ of the solution.

The protonation probability of site $i$ is given by a thermodynamic average over all possible protonation states (equation (2)):

$$
\left\langle x_{i}\right\rangle(\mathrm{pH})=\frac{\sum_{n=1}^{2^{N}} x_{i}^{n} \mathrm{e}^{-G_{n}(\mathrm{pH}) / R T}}{\sum_{n=1}^{2^{N}} \mathrm{e}^{-G_{n}(\mathrm{pH}) / R T}}
$$

Evaluating protonation probabilities by equation (2) is usually too time-consuming for proteins with more than 25 titratable residues. In such cases, a Monte Carlo algorithm can be applied, ${ }^{26,41,42}$ which was also done in this study. Details are given in Methods.

When two titratable sites titrate in the same $\mathrm{pH}$ range and interact strongly with each other, their titration is usually correlated, i.e. the protonation of one site depends on the protonation of the other site. The correlation $c_{i j}$ between the protonation of two sites $i$ and $j$ can be defined by the difference between the probability $\left\langle x_{i} x_{j}\right\rangle$ of having site $i$ and site $j$ protonated at the same time and the product of the probabilities $\left\langle x_{i}\right\rangle$ and $\left\langle x_{j}\right\rangle$ of having site $i$ or site $j$ protonated

$$
c_{i j}=\left\langle x_{i} x_{j}\right\rangle-\left\langle x_{i}\right\rangle\left\langle x_{j}\right\rangle
$$

A positive value for $c_{i j}$ shows that site $i$ and site $j$ tend to be protonated at the same time, a negative value indicates that site $i$ tends to be protonated when site $j$ is deprotonated and vice versa. A value of zero indicates no correlation. One can demonstrate that in this context here, the maximum value for positive correlation is 0.25 and the maximum value for negative correlation is -0.25 .

\section{Accounting for a transmembrane proton gradient in $\mathrm{pH}$ titration}

In the case of transmembrane proteins, the residues exposed to different sides of the membrane may experience different proton concentrations. In this study, we develop a scheme to account for the transmembrane $\mathrm{pH}$ gradient and analyze its effect on the protonation probabilities of the protein titratable sites.

A transmembrane protein with $N$ sites connected to the extracellular region (EC) and $K$ sites connected to the cytoplasmic region $(\mathrm{CP})$ has $2^{N+K}$ protonation states. The energy $G_{n}$ of the $n$th protonation state is given by equation (4):

$$
\begin{aligned}
& G_{n}\left(\mathrm{pH}_{\mathrm{EC}}, \mathrm{pH}_{\mathrm{CP}}\right) \\
& =\sum_{i=1}^{N}\left(\left(x_{i}^{n}-x_{i}^{\mathrm{o}}\right) R T \ln 10\left(\mathrm{pH}_{\mathrm{EC}}-\mathrm{p} K_{\mathrm{a}, i}^{\mathrm{intr}}\right)\right) \\
& \quad+\frac{1}{2} \sum_{i=1}^{N} \sum_{j=1}^{N}\left(W_{i j}\left(x_{i}^{n}-x_{i}^{\mathrm{o}}\right)\left(x_{j}^{n}-x_{j}^{\mathrm{o}}\right)\right) \\
& \quad+\sum_{r=1}^{K}\left(\left(x_{r}^{n}-x_{r}^{\mathrm{o}}\right) R T \ln 10\left(\mathrm{pH}_{\mathrm{CP}}-\mathrm{p} K_{\mathrm{a}, r}^{\mathrm{intr}}\right)\right) \\
& \quad+\frac{1}{2} \sum_{r=1}^{K} \sum_{s=1}^{K}\left(W_{r s}\left(x_{r}^{n}-x_{r}^{\mathrm{o}}\right)\left(x_{s}^{n}-x_{s}^{\mathrm{o}}\right)\right) \\
& \quad+\sum_{i=1}^{N} \sum_{r=1}^{K}\left(W_{i r}\left(x_{i}^{n}-x_{i}^{\mathrm{o}}\right)\left(x_{r}^{n}-x_{r}^{\mathrm{o}}\right)\right)
\end{aligned}
$$

where the sites $i$ and $j$ belong to the $N$ sites connected to the $\mathrm{EC}$ region with $\mathrm{pH}_{\mathrm{EC}}$, and the sites $r$ and $s$ belong to the $K$ sites connected to the $\mathrm{CP}$ region with $\mathrm{pH}_{\mathrm{CP}}$. It is assumed here that the proton gradient is counter balanced by an appropriate ion gradient leading to a zero membrane potential, a scenario that is possible in experimental setups., In principle, it is also possible to account for nonzero membrane potentials in the framework of the 
Poisson-Boltzmann equation. ${ }^{43}$ The expression of $G_{n}$ is the sum of the energy $G_{n}\left(\mathrm{pH}_{\mathrm{EC}}\right)$ of the $N$ sites connected to the EC region, the energy $G_{n}\left(\mathrm{pH}_{\mathrm{CP}}\right)$ of the $K$ sites connected to the $\mathrm{CP}$ region, and the cross-interactions between the $N$ and $K$ sites. The energy $G_{n}$ of the state $n$ depends on the $\mathrm{pH}$ values of the EC and $\mathrm{CP}$ regions separated by the membrane. The protonation probability $\left\langle x_{i}\right\rangle$ of the site $i$ is obtained from equation (2) by summing over all $2^{N+K}$ states, and thus depends also on the $\mathrm{pH}$ values of the $\mathrm{EC}$ and $\mathrm{CP}$ regions.

\section{Connectivity of the titratable sites to the extracellular or the cytoplasmic region}

In equation (4), each titratable site of the protein must be accessible for protons either from the extracellular space or from the cytoplasm. In proton pumps such as BR, the titratable sites which participate in the proton transfer interact via an extensive hydrogen-bond network. ${ }^{44,45}$ The vectorial proton transfer requires that the hydrogen-bond network is not continuous all along the protein, otherwise the protein becomes a non-vectorial proton channel. ${ }^{46}$ Therefore, two or more distinct parts of the hydrogen-bond network relate the titratable residues to either the cytoplasm or the extracellular region in proton pumps. ${ }^{47-50}$ Connecting the sites to the bulk solvent thus requires first to find the hydrogen-bond network in the protein, and second to search for proton transfer paths that connect the titratable residues to either the $\mathrm{EC}$ or the $\mathrm{CP}$ region.

Hydrogen bonds can be identified from the atomic positions of the polar groups in the protein These groups involve protein residues, bound ligands (such as the retinal chromophore in BR), and buried water molecules which are known to participate in the proton transfer. ${ }^{46,51,52}$ Buried water molecules are often not seen in crystal structures because of their high mobility or low occupancy, ${ }^{53-55}$ which might result in apparent internal cavities in protein structures. Since such cavities can be filled with water, they must be considered while calculating the hydrogen bond network. Thus, the determination of the protein hydrogen-bond network requires the identification of all relevant donors/acceptors and the internal cavities. Finally, the hydrogen bonds between solvent-accessible polar residues and the bulk water must be identified to connect the hydrogen-bond network to the $\mathrm{CP}$ and the EC regions.

The hydrogen-bond network is then represented as a mathematical graph, where polar groups as well as the EC and CP regions are nodes and hydrogen bonds are vectorial arcs. A graphtheoretical method is employed to search the graph for connections between every titratable site and the $\mathrm{EC}$ or the $\mathrm{CP}$ region. Thus, for each residue that belongs to the hydrogen bond network, it is possible to detect whether it is connected to either the $\mathrm{EC}$ or $\mathrm{CP}$ region, both regions, or none.

\section{Results and Discussion}

\section{Protein, membrane and solvent environments}

BR contains 39 titratable sites in the residue range 5-231: seven arginine residues, eight aspartic acid residues, six glutamic acid residues, six lysine residues, 11 tyrosine residues, and the Schiff base (SB) linking the retinal chromophore with K216. Since BR is a transmembrane protein, the titratable sites face different environments, depending on their locations. Many functionally important titratable sites are buried within the protein core.

Table 1 summarizes the local environment of the titratable residues in BR. These data were obtained from the solvent accessibilities calculated with the structures embedded in the membrane (see Methods). Most sites are directly exposed to the solvent (20 residues). The others are buried inside the protein (12 residues), face the hydrophobic part of the membrane (two residues) or lie at the interface of the solvent and the membrane (five residues). The sites pointing to the solvent of the cytoplasmic region are the most numerous (14 sites), while only six titratable residues are exposed to the extracellular region. This inbalance is explained by the offset of the membrane bilayer with respect to the protein center: the protein surface exposed to the EC region is smaller than that exposed to the cytoplasm. ${ }^{52,56}$ Twelve titratable sites are located within the protein core: the retinal Schiff base, several key residues potentially involved in the proton transfer (R82, D85, D96, D115, E194, E204, D212), and most tyrosine residues. All sites in the protein interior are not directly accessible from the bulk, though they might have hydrophilic contacts with water molecules buried inside protein cavities. Most of the titratable sites known to participate in the proton transfer interact with internal crystallographic water molecules. ${ }^{44,52}$

\section{Global hydrogen-bond network}

The hydrogen-bond network was calculated for three ground-state structures of $\mathrm{BR}\left(1 \mathrm{C} 3 \mathrm{~W},{ }^{57}\right.$ $1 \mathrm{KGB}^{58}$ and $1 \mathrm{KME}^{59}$ ) to determine the residue connectivities to the bulk. Figure 1 depicts the hydrogen-bond network obtained for 1C3W. The hydrogen-bond networks obtained for 1KGB and $1 \mathrm{KME}$ are very similar. The network consists of several parts: the side-chain hydrogen bonds as determined by geometrical criteria; hydrogen bonds connecting residues lining the protein cavities which are assumed to contain at least temporarily water molecules; and additional hydrogen bonds connecting the solvent-accessible residues to either the EC or the $\mathrm{CP}$ region. These three parts are analyzed in the following paragraphs.

The first part of the global hydrogen-bond network consists of the side-chain-side-chain hydrogen bonds which are calculated according to geometrical criteria (see Methods). On the 
Table 1. Solvent exposure and connectivities for the titratable sites in bacteriorhodopsin

\begin{tabular}{|c|c|c|c|c|c|}
\hline Titratable site & Local environment $^{\mathrm{a}}$ & Connection to $\mathrm{EC}$ or $\mathrm{CP}$ & Titratable site & Local environment $^{a}$ & Connection to $\mathrm{EC}$ or $\mathrm{CP}$ \\
\hline R7 & $\mathrm{S}$ & EC & K129 & $S$ & EC \\
\hline E9 & S & EC & Y131 & $\mathrm{S}$ & $\mathrm{EC}$ \\
\hline Y26 & M & $\mathrm{CP}$ & Y133 & $\mathrm{M} / \mathrm{S}$ & EC \\
\hline K30 & $S$ & $\mathrm{CP}$ & $\mathrm{R} 134^{\mathrm{b}}$ & $\mathrm{P}$ & EC \\
\hline D36 & S & $\mathrm{CP}$ & Y147 & M & $\mathrm{CP}$ \\
\hline D38 & $S$ & $\mathrm{CP}$ & Y150 & $\mathrm{M} / \mathrm{S}$ & $\mathrm{CP}$ \\
\hline K40 & $\mathrm{S}$ & $\mathrm{CP}$ & K159 & S & $\mathrm{CP}$ \\
\hline K41 & $S$ & $\mathrm{CP}$ & E161 & S & $\mathrm{CP}$ \\
\hline Y43 & S & $\mathrm{CP}$ & R164 & S & $\mathrm{CP}$ \\
\hline Y57 & $\mathrm{P}$ & EC & E166 & S & $\mathrm{CP}$ \\
\hline Y64 & $\mathrm{M} / \mathrm{S}$ & EC & K172 & $\mathrm{S}$ & $\mathrm{CP}$ \\
\hline E74 & S & EC & R175 & $\mathrm{M} / \mathrm{S}$ & $\mathrm{CP}$ \\
\hline Y79 & $\mathrm{S}$ & EC & Y185 & $\mathrm{P}$ & EC \\
\hline R82 & $\mathrm{P}$ & EC & E194 & $\mathrm{P}$ & EC \\
\hline Y83 & $\mathrm{P}$ & EC & E204 & $\mathrm{P}$ & EC \\
\hline D85 & $\mathrm{P}$ & EC & D212 & $\mathrm{P}$ & EC \\
\hline D96 $6^{\mathbf{b}}$ & $\mathrm{P}$ & $\mathrm{CP}$ & $\mathrm{SB}^{\mathrm{c}}$ & $\mathrm{P}$ & EC \\
\hline D102 & $\mathrm{S}$ & $\mathrm{CP}$ & R225 & $\mathrm{M} / \mathrm{S}$ & $\mathrm{CP}$ \\
\hline D104 & $\mathrm{S}$ & CP & R227 & S & $\mathrm{CP}$ \\
\hline $\mathrm{D} 115^{\mathbf{b}, \mathbf{d}}$ & $\mathrm{P}$ & $\mathrm{CP}$ or $\mathrm{EC}$ & & & \\
\hline
\end{tabular}

${ }^{a}$ Local environment of the residue: $\mathrm{S}$, solvent-exposed; $\mathrm{P}$, buried inside the protein; $\mathrm{M}$, facing the membrane; combinations denote residues at the interface.

b Residues that are manually assigned according to experimental data and visual inspection; non-titrating S193 is manually connected to the EC region.

c Schiff base between the retinal and K216.

d Alternate connections (see Figure 4).

extracellular side of the protein, most noticeable are the hydrogen bonds between the carboxylate groups of D85 and T89, the two hydrogen bonds of D212 with its neighboring residues Y185 and Y57, the hydrogen bond between S193 and E204, and the hydrogen bond between the two glutamic acid residues E194 and E204. On the cytoplasmic side of the protein, we find a hydrogen bond between D96 and T46 and another one between D115 and T90. These side-chain-side-chain hydrogen bonds are consistent with earlier descriptions of the hydrogen-bond network in BR. ${ }^{12,57}$ They represent, however, only a subset of this network, since many hydrogen bonds found in the crystal structures involve water molecules buried in the protein. In our study, we represent such buried water molecules as internal cavities in the protein.

The second part of the global hydrogen-bond network consists of the hydrogen bonds formed between the protein side-chains containing hydrogen-bond donors/acceptors and protein internal cavities. Table 2 reports the internal cavities found in the $1 \mathrm{C} 3 \mathrm{~W}$ structure. Similar cavities are found in $1 \mathrm{KGB}$ and $1 \mathrm{KME}$. The largest cavity $\left(105 \AA^{3}\right.$ in $1 \mathrm{C} 3 \mathrm{~W})$ contains the three crystallographic water molecules 403, 404, and 405. It is located at the extracellular side of the protein between R82 and the two glutamic acid residues E194 and E204. R82, E194/E204, and the water molecules contained in the cavity constitute the so-called proton release complex. ${ }^{12}$ The volume of this large cavity suggests the possibility to accommodate more water molecules than those observed in the crystal. A cavity located between D85 and R82 holds the water molecules 401 and 406 and is closely neigh- bored by the cavity that holds water 402. These two cavities are merged in $1 \mathrm{KGB}$ and $1 \mathrm{KME}$. Many cavities do not contain any crystal water molecules, although their volume can be as large as $59 \AA^{3}$. Furthermore, at least one polar sidechain contributes to the formation of several empty cavities. Empty cavities might thus contain highly mobile water molecules potentially participating in the proton transfer. We assume here that all cavities found in the structures are at least temporarily filled with water. Hence, the hydrogen-bond donors and acceptors of the lining protein side-chains are connected to the cavity with additional hydrogen bonds. Those residues are given in bold in Table 2. The hydrogen bonds between protein side-chains and cavities represent a large subset of the global hydrogen-bond network (Figure 1).

The third part of the global hydrogen-bond network consists of the hydrogen bonds formed between the solvent-accessible polar side-chains of the protein and the bulk. Since the protein is embedded in the membrane, its solvent-accessible surface is unambiguously divided into two distinct parts, EC and CP. Thus, the polar side-chains accessible from the cytoplasm form hydrogen bonds with the solvent of the CP region only. Similarly, the polar side-chains accessible from the extracellular region form hydrogen bonds with the solvent of the EC region only. For clarity, these hydrogen bonds are represented schematically in Figure 1 as yellow lines connecting the solventaccessible residues and either the EC or the $\mathrm{CP}$ region. The solvent accessibility of the BR residues was obtained from the cavity detection algorithm 


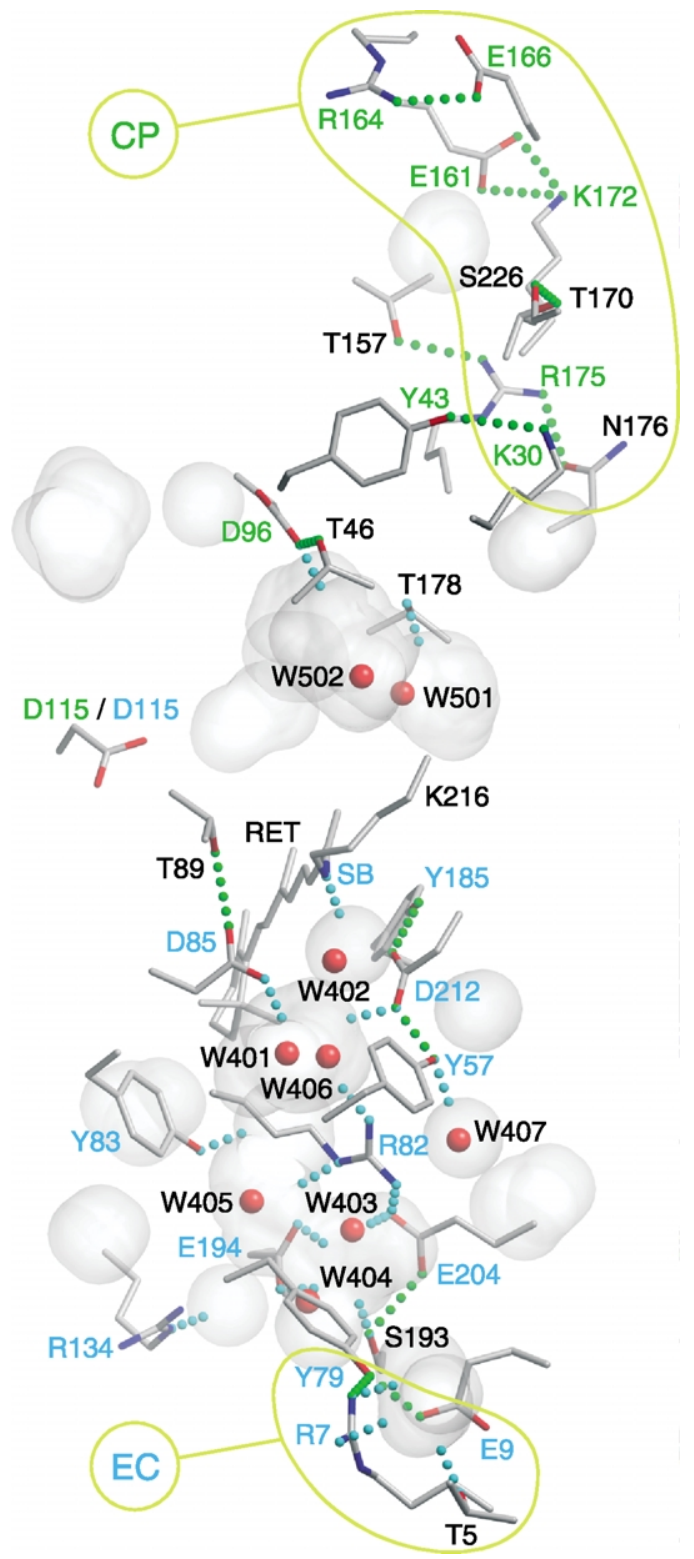

Figure 1. Global hydrogen-bond network for the 1C3W model. EC and CP mark the extracellular and cytoplasmic region, respectively. Hydrogen bonds calculated according to the geometrical criteria of Figure 7 are shown by green dotted lines. Protein internal cavities are depicted as transparent surfaces, and crystallographic water molecules as red balls. The polar sidechains lining the cavities form additional hydrogen bonds with the cavities (cyan dotted lines). Solventaccessible residues (contoured in yellow) are hydrogenbonded to the bulk. The titratable sites accessible from the $\mathrm{CP}$ region are labelled in green, while those accessible from the EC region are labelled in blue. The hydrogen bond between D115 and T90 is omitted for clarity.

(see Methods). The side-chain hydroxyl group of S193 does not point to the bulk directly but instead interacts with E204 (as noted above) and E194 in the protein core. These two glutamic acid residues belong to the proton release complex, which releases the proton to the bulk. ${ }^{60}$ The temperature
Table 2. Internal cavities in $1 \mathrm{C} 3 \mathrm{~W}$

\begin{tabular}{|c|c|c|c|}
\hline Cavity $^{a}$ & Volume $^{\mathbf{b}}$ & $\begin{array}{l}\text { Water } \\
\text { molecules }^{c}\end{array}$ & Contributing residues $^{\mathrm{d}}$ \\
\hline 1 & 105.2 & $403,404,405$ & $\begin{array}{l}\text { P77, Y79, R82, Y83, W86, } \\
\text { W189, S193, E194, L201, } \\
\text { E204, F208 }\end{array}$ \\
\hline 2 & 79.2 & 501 & $\begin{array}{l}\text { L93, L94, L97, V177, T178, } \\
\text { L181, W182, A215, F219 }\end{array}$ \\
\hline 3 & 59.0 & - & $\begin{array}{l}\text { P91, L94, L95, A98, I108, } \\
\text { L111, V112 }\end{array}$ \\
\hline 4 & 57.6 & 401,406 & $\begin{array}{l}\text { M56, Y57, M60, R82, D85, } \\
\text { W86, D212 }\end{array}$ \\
\hline 5 & 48.1 & 502 & $\begin{array}{l}\text { T46, V49, P50, L93, D96, } \\
\text { K216 , F219 }\end{array}$ \\
\hline 6 & 43.2 & - & $\begin{array}{l}\text { L94, M118, M145, I148, L149, } \\
\text { L152, T178, W182 }\end{array}$ \\
\hline 7 & 40.9 & - & T5, R7, E9, W10, L13, L61 \\
\hline 8 & 27.2 & - & $\begin{array}{l}\text { V188, I191, G192, V199, } \\
\text { E204, L207 }\end{array}$ \\
\hline 9 & 25.0 & - & $\begin{array}{l}\text { G122, G125, W137, W138, } \\
\text { W189, RET }\end{array}$ \\
\hline 10 & 18.1 & - & $\begin{array}{l}\text { Y26, A160, E161, M163, } \\
\text { F171, K172 }\end{array}$ \\
\hline 11 & 17.6 & - & $\begin{array}{l}\text { T157, A160, E161, M163, } \\
\text { F171, K172 }\end{array}$ \\
\hline 12 & 16.6 & - & $\begin{array}{l}\text { I78, W80, Y83, L123, A126, } \\
\text { L127 }\end{array}$ \\
\hline 13 & 16.3 & - & $\begin{array}{l}\text { Y131, R134, F135, E194, } \\
\text { G195 }\end{array}$ \\
\hline 14 & 14.7 & - & G16, M20, Y57, M209, V213 \\
\hline 15 & 12.8 & - & L94, L97, L111, L152, F156 \\
\hline 16 & 11.7 & 402 & M20, A53, Y57, D85, SB ${ }^{\mathbf{e}}$ \\
\hline 17 & 11.1 & 407 & Y57, R82, T205, M209 \\
\hline \multicolumn{4}{|c|}{$\begin{array}{l}\text { a Cavities are sorted by volumes. } \\
\text { b Volume (in } \AA^{3} \text { ) of the cavity computed from its molecular } \\
\text { surface. }{ }^{104} \\
\text { c Crystallographic water molecules found in the cavities. } \\
\text { d Residues in bold form a hydrogen bond between their polar } \\
\text { side-chain and the cavity. } \\
\text { e K216, lysine moiety of the retinal Schiff base; RET, retinal } \\
\text { moiety; SB, Schiff base proton donor. }\end{array}$} \\
\hline
\end{tabular}

factors of S193, E194 and E204 are higher than those of the neighboring residues, indicating that they are more flexible. The higher flexibility of this region makes it likely that the hydroxyl group of S193 is also accessible from the bulk in some conformations. Hence, we considered that the S193 polar side-chain forms a hydrogen bond with the EC region as well as with E204.

\section{Connectivities of the titratable residues to the bulk}

Table 1 reports the solvent connectivities obtained for all 39 titratable residues by searching the global hydrogen-bond network with a graphtheoretical algorithm (see Methods). Thirty-six residues out of 39 were automatically and uniquely connected to either the $\mathrm{CP}$ or the EC region. The remaining unconnected residues are R134, D96, and D115. R134 does not form hydrogen bonds with the side-chains of its surrounding residues, and thus cannot be connected to the solvent. However, the distance of its side-chain charged group to the carboxyl group of E194 is 5-6 A. Due to its 
proximity to the residues of the proton release complex, we connected R134 to the EC region. According to our titration calculations presented below, this choice does not influence our results, since R134 is predicted to be always protonated.

The residues D96 and D115 are located at the cytoplasmic side of the protein. In the groundstate of BR, D96 is not accessible to the solvent due to the shielding caused by F42. ${ }^{61}$ However, it is well established that D96 is directly involved in the reprotonation of the Schiff base from the cytoplasm at later stages of the photocycle. ${ }^{12}$ This residue was consequently connected to the $\mathrm{CP}$ region. The connectivity of D115 is not as obvious. It is located in the protein core, about $7 \AA$ away from the Schiff base and from the $\beta$-ionone ring of the retinal ${ }^{47}$ (see Figures 1 and 2). D115 and D96 are the only protonated aspartic acid residues in the groundstate of $\mathrm{BR}^{, 62}$ and are likely to interact with each other. ${ }^{63}$ However, D115 might not participate in the reprotonation of the retinal from the

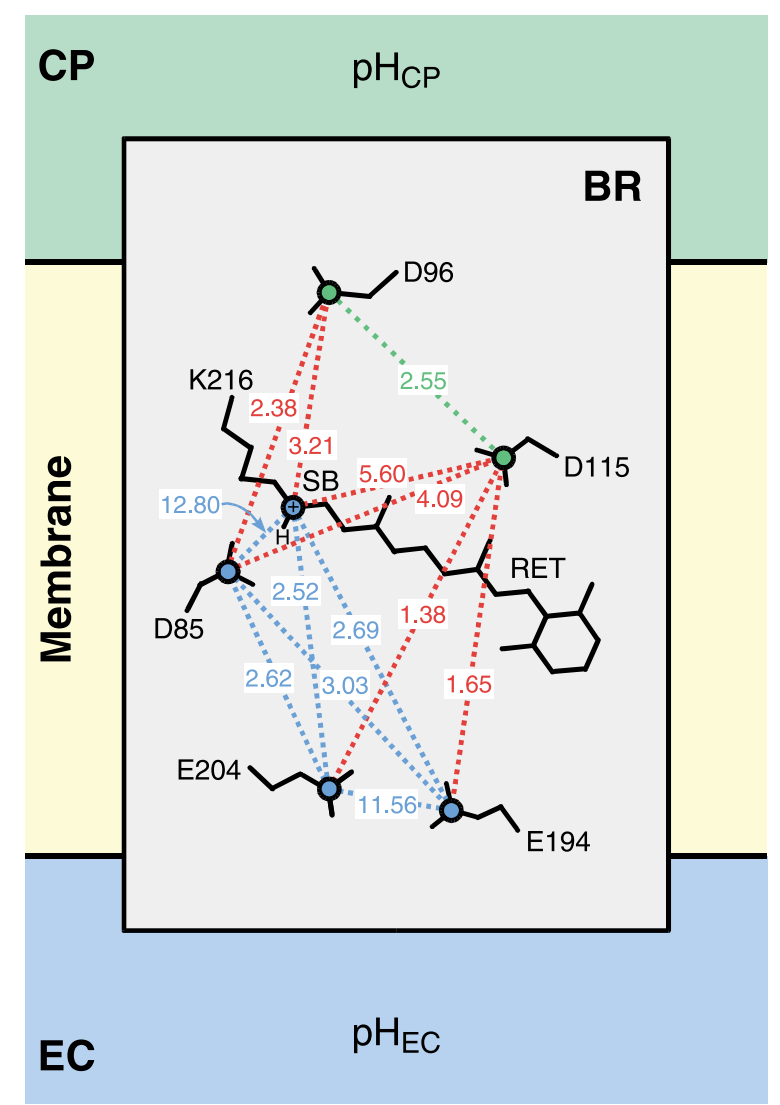

Figure 2. Interaction energies between selected BR residues in 1C3W. The cytoplasm $(\mathrm{CP})$ and extracellular (EC) regions are represented, respectively, as green and blue areas. The residues connected to the CP or EC regions, as well as their interaction energies (in kcal/ $\mathrm{mol})$, are depicted with the corresponding colors. The interaction energies colored in red denote residues connected to different solvent regions. D115 is represented here as connected to the $\mathrm{CP}$ region, but the alternate connectivity to EC is also considered (see the text and Figure 4). cytoplasm. ${ }^{64}$ There is thus no clear experimental evidence that D115 is connected to the $\mathrm{CP}$ region. Because the titration of D115 may influence other residues that titrate in the same $\mathrm{pH}$ range, we connected this residue to the $\mathrm{CP}$ region for one set of calculations, and to the EC region for another. However, since D115 is located in the cytoplasmic part of $\mathrm{BR}$, we favor the assignment to the $\mathrm{CP}$ region. Moreover, D115 is in proximity to a large cavity (cavity 6 in Table 2), which might connect this residue with the cytoplasmic region if protein motion is considered.

\section{Long-range electrostatic interactions within the protein}

Continuum electrostatics calculations were performed to obtain the different contributions to the protonation state energies $G n$ of the protein (equation (4)). Since BR is found in the membrane of Halobacterium salinarum, an extremophile archaeum that lives at very high salt concentrations, ${ }^{65}$ the mobile ions in solution were accounted for in the calculations. The intrinsic $\mathrm{p} K_{\mathrm{a}}^{\mathrm{intr}}$ values and the site-site interaction energies $W_{i j}$ were calculated by solving twice the PoissonBoltzmann equation for each titratable site and for its model compound ${ }^{24,26}$ (see Methods). Neither the interactions energies $W_{i j}$ nor the intrinsic $\mathrm{p} K_{\mathrm{a}}^{\mathrm{intr}}$ values depend on whether a site is connected to the $\mathrm{EC}$ or the $\mathrm{CP}$ region.

Figure 2 shows the interactions energies $W_{i j}$ between several important titrating residues of $\mathrm{BR}$ obtained for $1 \mathrm{C} 3 \mathrm{~W}$. Only the interactions above $1 \mathrm{kcal} / \mathrm{mol}$ are depicted for every pair of residues among the Schiff base, D85, D96, D115, E194, and E204. The R82 and D212 residues are not shown since they do not titrate in the investigated $\mathrm{pH}$ range. The titratable sites and their interaction energies are colored according to the residue connectivity given in Table 1 . The strongest interactions are found between D85 and the Schiff base $(12.80 \mathrm{kcal} / \mathrm{mol})$ and between E194 and E204 $(11.56 \mathrm{kcal} / \mathrm{mol})$. The sites in the pairs D85-Schiff base and E194-E204 are thus likely to be in different protonation states over a wide range of $\mathrm{pH}$. D115 strongly interacts with the Schiff base, D85, and D96 (respectively, 5.60, 4.09 and $2.55 \mathrm{kcal} / \mathrm{mol}$ ). The titrations of the three aspartic acid residues D85, D96, and D115 thus influence each other, particularly since D85 and D96 are connected to different solvent regions.

The presence of a membrane region in our calculations creates a low-dielectric environment which does not shield the electrostatic interactions as strongly as the bulk water. As a consequence, the electrostatic interactions between the titratable sites in the protein are relatively high even at long distances. Interestingly, the titratable sites located near the retinal (D85, D115, the Schiff base) interact significantly with a residue near the cytoplasm (D96) and other residues near the extracellular region (E194, E204). When the $\mathrm{pH}$ differs at the 
two sides of the membrane, the long-range electrostatic interactions that occur along the membrane normal can play an important role in the titration of the residues buried deeply in the protein core.

\section{Irregular titration curves and the effect of the pH gradient}

For a single titratable site in solution, the protonation probability as a function of $\mathrm{pH}$ gives a Henderson-Hasselbalch sigmoidal curve. However, the titration curve of a titratable residue that interacts with other titratable sites in a protein may deviate from the sigmoidal curve. The halfprotonation point (or $\mathrm{p} K_{1 / 2}$ value) is obtained from the $\mathrm{pH}$ value where the protonation probability is 0.5 . Figure 3 shows the protonation probabilities obtained for three aspartic acid residues and the Schiff base of $1 \mathrm{C} 3 \mathrm{~W}$. The Schiff base is essentially always protonated with a protonation probability between 0.98 and 1.0. The aspartic acid residue D104 is a residue exposed to the cytoplasm. Its titration curve gives a halfprotonation point of 3.68 and has a Hill coefficient of 0.913. Thus, the titration behavior of D104 slightly deviates from the titration of an isolated aspartic acid residue $\left(\mathrm{p} K_{\mathrm{a}}=4\right)$. In contrast, the titration curves of D85 and D115 clearly deviate from a standard sigmoidal curve. Such irregular titration curves have also been observed in previous experimental ${ }^{66,67}$ and theoretical studies $^{27,29,33,34}$ without the presence of a transmembrane proton gradient. They occur as a result of the strong electrostatic interactions between the residues that titrate at the same $\mathrm{pH}$ range.

The titration behavior of titratable sites in trans-

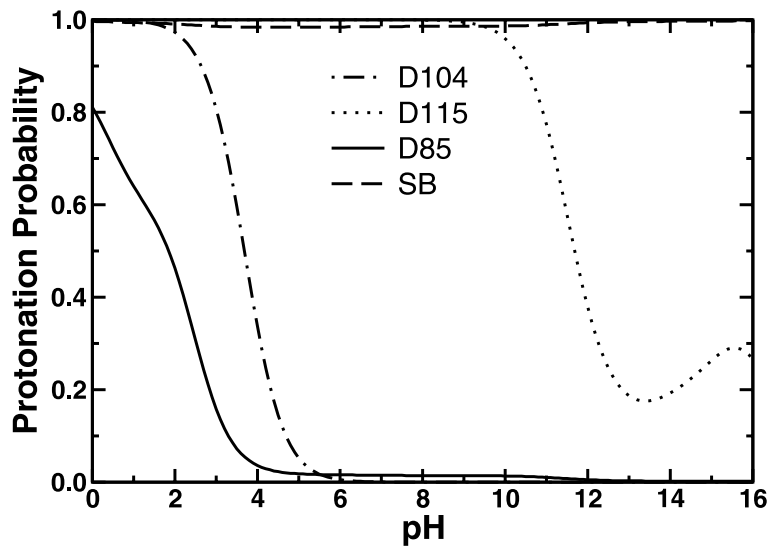

Figure 3. One-dimensional titration curves of selected $\mathrm{BR}$ residues using the $1 \mathrm{C} 3 \mathrm{~W}$ model. No proton gradient was applied in this case. These titration curves correspond to the titration curves on the diagonal of the twodimensional plots in Figures 4 and 5. The protonation probability of D85, D104, D115 and the retinal Schiff base (SB) are plotted as a function of $\mathrm{pH}$. The ionic strength is $1 \mathrm{M}$. All sites but D104 (broken-dotted curve) show an irregular titration behavior that deviates significantly from the standard Henderson-Hasselbalch sigmoidal curve. membrane proteins can be even more complicated, since the $\mathrm{pH}$ at the two sides of the membrane may differ. The protonation probabilities calculated here as a function of the $\mathrm{pH}$ in the $\mathrm{CP}$ region and the $\mathrm{pH}$ in the EC region lead to two-dimensional titration curves. Figure 4 shows the 2D titration curves obtained for a representative set of titratable sites in BR. A titration curve as a function of a single $\mathrm{pH}$ as in Figure 3 corresponds to the protonation probability obtained along the diagonal $\mathrm{pH}_{\mathrm{EC}}=$ $\mathrm{pH}_{\mathrm{CP}}$ of the 2D titration curves. The effect of connecting D115 to the $\mathrm{CP}$ region or to the $\mathrm{EC}$ region is shown in Figure $4 a$ and $b$, respectively. The protonation probability is color-coded, and contour lines give details in areas where the probability is close to 0 or 1 . Figure 5 shows the influence of the ionic strength and conformational variability between the three BR structures for the Schiff base and D85. The combined effects of $\mathrm{pH}$ gradient, ionic strength, and conformational variability are analyzed in the following paragraphs.

Among the 39 titratable sites of BR, six show an irregular titration behavior that reflects the influence of the $\mathrm{pH}$ gradient across the membrane. These sites are the aspartic acid residue D85, D96, D115, the glutamic acid residues E194, E204, and the Schiff base. In contrast, the titration of the other titrating residues depends only on the $\mathrm{pH}$ of either the EC or the CP region, as shown for D104 and E74 in Figure 4a. Several residues do not titrate at all within the investigated $\mathrm{pH}$ range. These nontitrating residues are tyrosine residues (always protonated), R82 (always protonated), and D212 (always deprotonated). Their constant protonation over large $\mathrm{pH}$ ranges are consistent with experimental data ${ }^{62,66,68,69}$ and previous theoretical calculations. $^{33}$

The protonation probability of D85 depends on the $\mathrm{pH}$ at the two sides of the membrane. This key residue is the first proton acceptor after the retinal becomes deprotonated during the $\mathrm{L}$ to $\mathrm{M}$ transition of the BR photocycle. ${ }^{12}$ According to experiments, D85 is deprotonated while the Schiff base is protonated in ground-state BR. Figures 4 and 5 show that D85 is predicted to be mostly deprotonated, which is consistent with the experimental $\mathrm{p} K_{\mathrm{a}}$ value of 2 obtained in high salt concentration. ${ }^{70}$ In physiological $\mathrm{pH}$ range, our calculations show that the protonation probability of D85 varies slightly between 0.01 and 0.12 as a consequence of minor conformational variations between the structures (Figure 5). This residue becomes fully deprotonated only at very high $\mathrm{pH}$ values, as shown by the contour line corresponding to a protonation probability of 0.01 . Although those $\mathrm{pH}$ values are quite high, the titration behavior of D85 is influenced by $\mathrm{pH}_{\mathrm{CP}}$ and not only by $\mathrm{pH}_{\mathrm{EC}}$ to which it is connected. This effect is also observed in the titration behavior of $\mathrm{D} 85$ at $\mathrm{pH}_{\mathrm{CP}}$ above 7, where the contour lines are parallel with the diagonal (Figures $4 a$ and 5). However, the influence of $\mathrm{pH}_{\mathrm{EC}}$ is less pronounced when D115 is connected to the EC region, because in this 
a)
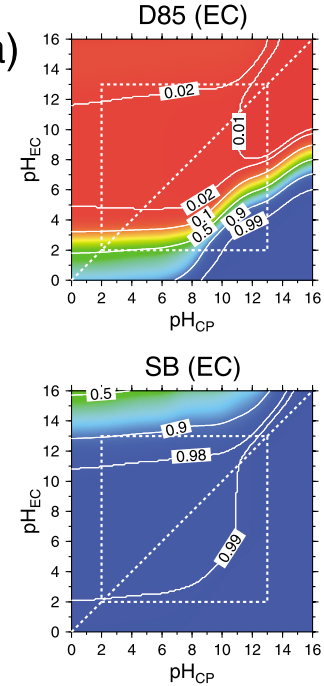

b)

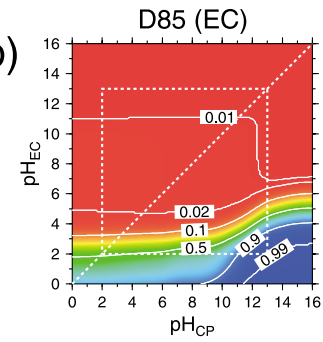

$\mathrm{SB}(\mathrm{EC})$

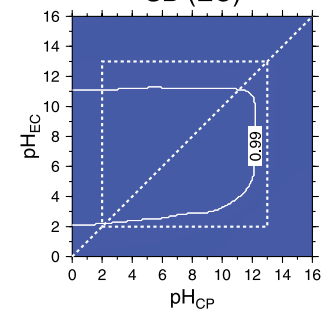

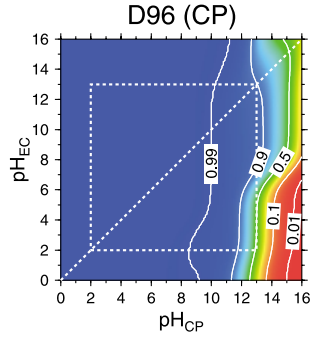
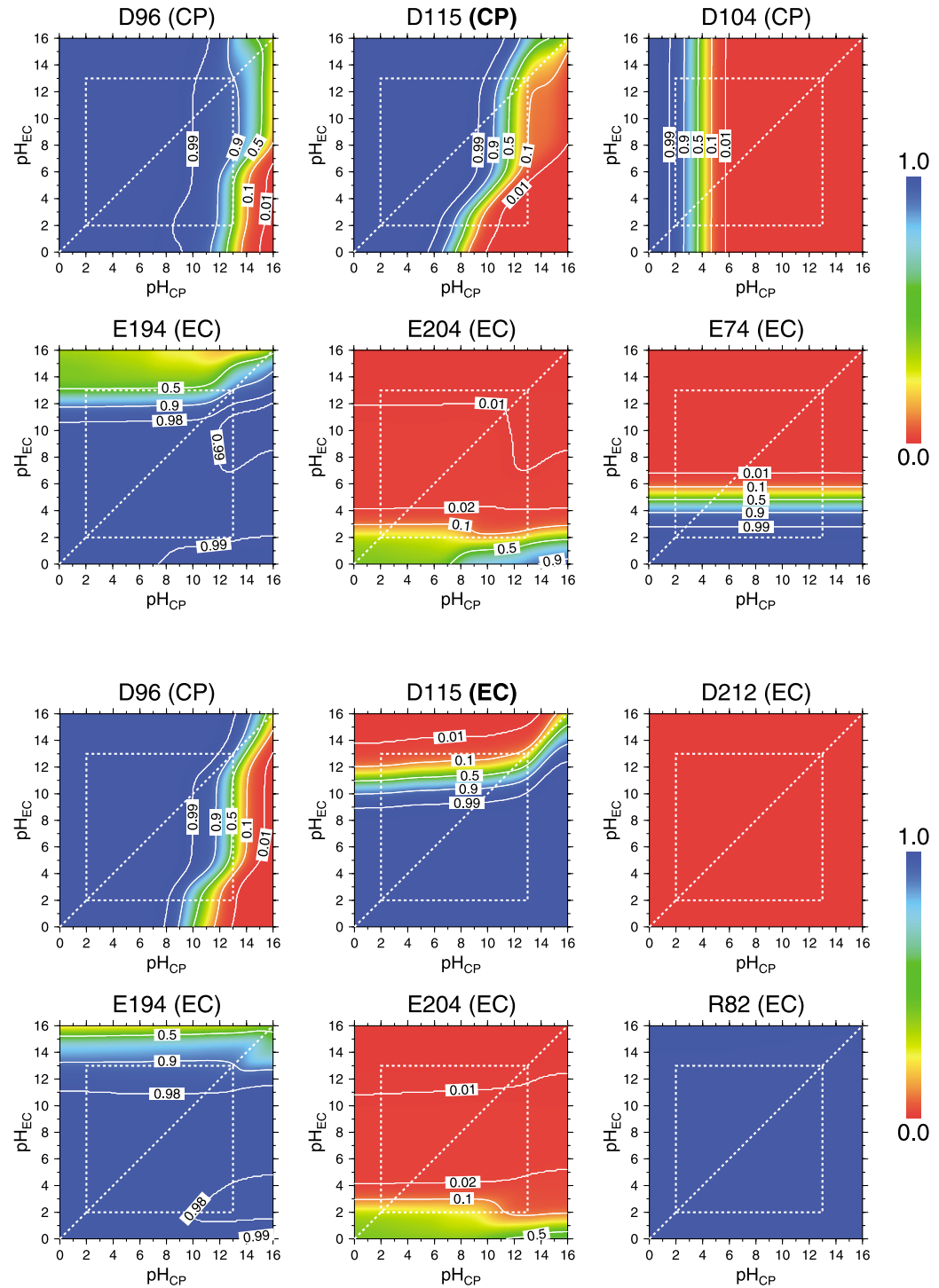

Figure 4. Two-dimensional titration curves of selected titratable sites in bacteriorhodopsin (1C3W model) as a function of $\mathrm{pH}_{\mathrm{CP}}$ and $\mathrm{pH}_{\mathrm{EC}}$. The ionic strength is $1 \mathrm{M}$. D115 is alternatively connected to (a) the cytoplasm or (b) the extracellular region. The protonation probability is color-coded according to the color gradient given on the right linear scale. Red, deprotonated; blue, protonated; green, half protonated; yellow and cyan show a probability of 0.25 and 0.75 , respectively. Selected level curves (in white) are depicted in uniform areas. The diagonal (broken line) represents a titration with $\Delta \mathrm{pH}=0$. The broken-line square shows the region delimited by the experimental $\mathrm{p} K_{\mathrm{a}}$ of $\mathrm{D} 85$ $\left(\mathrm{pK} K_{\mathrm{a}} \sim 2\right)^{70}$ and the Schiff base $\left(\mathrm{pK} K_{\mathrm{a}} \sim 13\right)^{71,72}$ obtained with no $\mathrm{pH}$ gradient. D104 and E74 are examples of BR sites where titration behavior depends only on $\mathrm{pH}_{\mathrm{CP}}$ or $\mathrm{pH}_{\mathrm{EC}}$, respectively. $\mathrm{D} 212\left(\mathrm{p} K_{\mathrm{a}}<1\right)^{62,66}$ and $\mathrm{R} 82\left(\mathrm{p} K_{\mathrm{a}} \sim 9.5\right.$ or $14)^{68,69}$ represent examples of sites which are always deprotonated (resp. protonated) over the whole $\mathrm{pH}$ ranges. The Figure was produced with the GMT program suite. ${ }^{103}$

situation D115 titrates only when $\mathrm{pH}_{\mathrm{EC}}$ is above 9 (Figure $4 \mathrm{~b}$ ). At $\mathrm{pH}_{\mathrm{CP}}$ below 7 , ionic strength $1 \mathrm{M}$, D85 titrates mainly as a function of $\mathrm{pH}_{\mathrm{EC}}$ with a protonation probability of 0.5 at $\mathrm{pH}$ values between 1.5 and 2.5 , depending on the structure. This result is in agreement with the titration curves obtained experimentally ${ }^{66,67}$ as well as in previous theoretical calculations. ${ }^{33,34}$

The protonation probability of the Schiff base is also influenced by the $\mathrm{pH}$ gradient. The Schiff base is predicted to be mostly protonated, which is consistent with the high $\mathrm{p} K_{\mathrm{a}}$ value of $12.4-13$ obtained experimentally. ${ }^{11,72}$ In our calculations, the Schiff base titrates only at very high extracellular $\mathrm{pH}$ values. Depending on the structure, the protonation probability varies between 0.99 in $1 \mathrm{C} 3 \mathrm{~W}$ to 0.88 in $1 \mathrm{KGB}$ (Figure 5). The titration curve of the Schiff base has a similar but antagonist behavior to D85: the Schiff base never becomes fully protonated at physiological $\mathrm{pH}$ values. This result reflects an interchange of the proton between the Schiff base and D85.

D96, which is buried within a hydrophobic environment near the cytoplasm (Figure 2), ${ }^{61}$ also has an irregular titration that is influenced by the $\mathrm{pH}$ gradient. Even at a long distance from the EC 


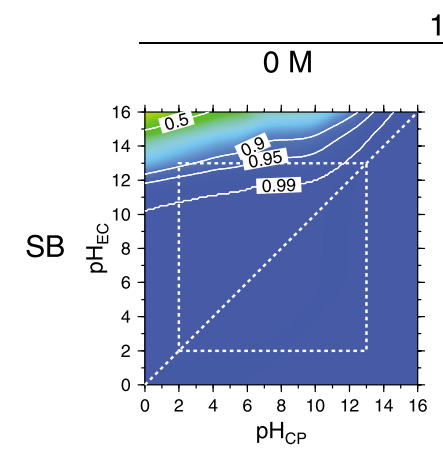

$1 \mathrm{C} 3 \mathrm{~W}$
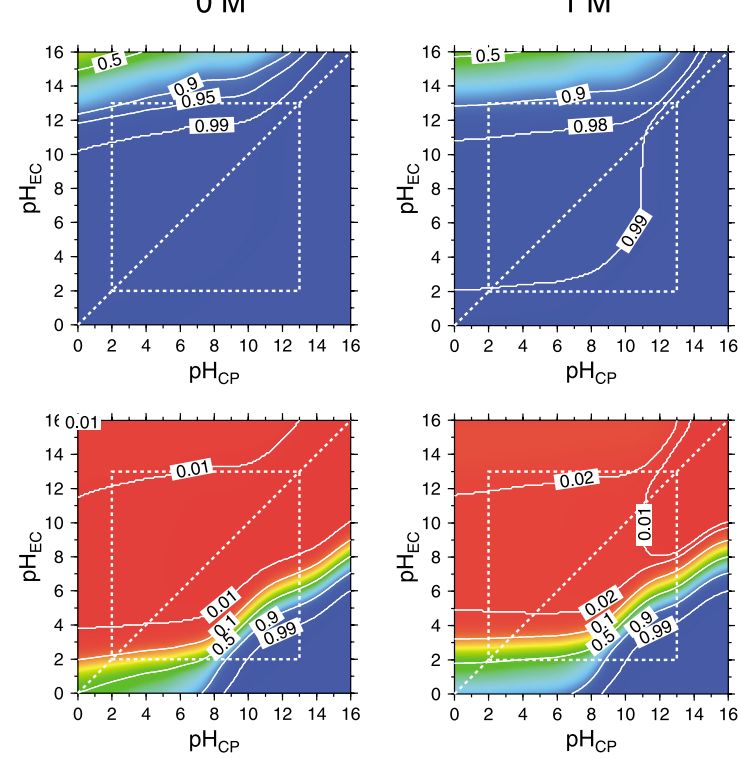
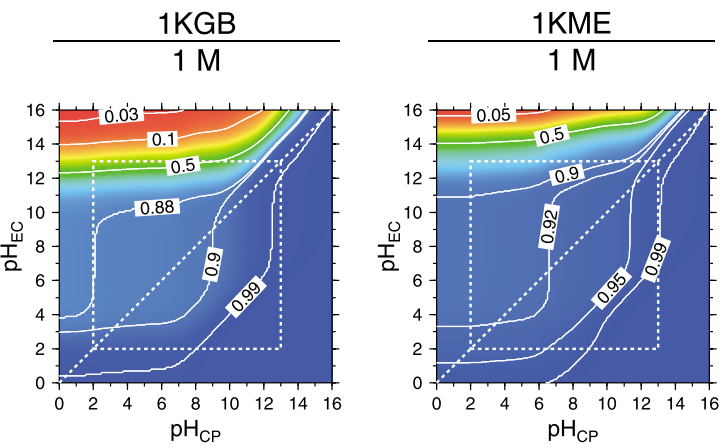

1.0
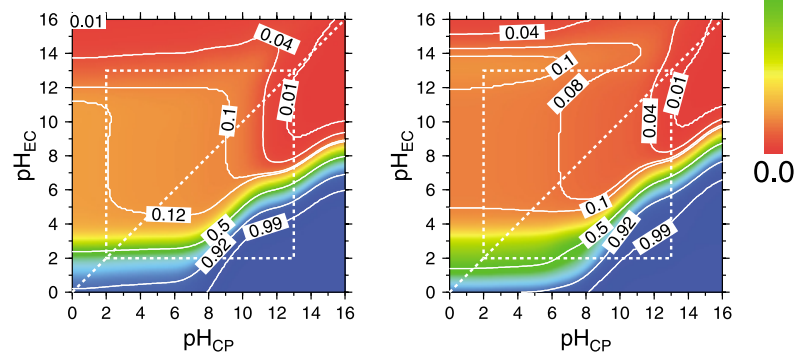

Figure 5. Effects of conformational variability and ionic strength on two-dimensional titration curves of bacteriorhodopsin. D85 and the Schiff base (SB) are shown for the three models studied. The 1C3W model shows the effect of the ionic strength when set to either 0 or $1 \mathrm{M}$. Color coding as in Figure 4.

region, D96 is affected by the extracellular $\mathrm{pH}$ as a result of the long-range electrostatic interactions. Our calculations predict that D96 is fully protonated at $\mathrm{pH}_{\mathrm{CP}}$ below 8 in the three ground-state structures of BR (Figure 4). This result is consistent with experiment. ${ }^{73-75}$ However, connecting the D115 residue to the EC region shifts the curves by about two $\mathrm{pH}$ units down the $\mathrm{pH}_{\mathrm{CP}}$ axis, because D115 is always protonated at $\mathrm{pH}_{\mathrm{EC}}$ below 8 . D96 is still fully protonated at $\mathrm{pH}_{\mathrm{CP}}$ below 8 . When $\mathrm{pH}_{\mathrm{EC}}$ is below 8 (Figure $4 \mathrm{a}$ ) or 5 (Figure $4 \mathrm{~b}$ ), the titration of D96 correlates with the titration of D85 since both residues have irregular titrations at low extracellular $\mathrm{pH}$.

According to experiments, D115 is protonated in ground-state BR. ${ }^{62}$ We find that its titration behavior is also influenced by the $\mathrm{pH}$ gradient. As mentioned above, this residue is completely buried in the protein core without direct connection to the cytoplasm or the extracellular region. For this reason, D115 was alternatively connected to either the $\mathrm{CP}$ or the EC region, and two sets of calculations were performed. Based on the localization of D115 at the cytoplasmic side of BR, we favor, however, the assignment of this residue to the cytoplasmic region. Presumably, the structural changes occurring along the photocycle will connect this residue to the cytoplasmic region. In agreement with experiment, D115 is predicted to be mostly protonated at physiological $\mathrm{pH}$ values. Our calculations show that the residue titrates at lower $\mathrm{pH}$ values than D96 (Figure 4a). Furthermore, when D115 is connected to the CP region (Figure 4a), the protonation probabilities of D115 and D85 correlate for $\mathrm{pH}_{\mathrm{EC}}$ between 4 and 8 and $\mathrm{pH}_{\mathrm{CP}}$ between 8 and 12. This correlation does not occur when D115 is connected to the EC region. While the role of this residue in the function of $B R$ is not clear, our results show that D115 affects the titration of D85, and thus possibly influences the first step of the proton transfer in the BR photocycle.

The last two residues having an irregular titration are E194 and E204. These glutamic acid residues are facing each other in the proton release complex and are strongly coupled electrostatically (Figure 2). Figure $4 a$ and $b$ show that, over wide pH ranges, E194 is mostly protonated while E204 is essentially deprotonated. This result is consistent with recent titration calculations of ground-state $\mathrm{BR}^{33}$ performed in similar conditions, i.e. without explicit water molecules in the protein cavities. Even though D204 is predicted to be protonated in some experiments, ${ }^{76}$ the individual protonation states of E194 and E204 are unknown, since only a global $\mathrm{p} K_{\mathrm{a}}$ value of 9.5 is given for the proton release complex as a whole. ${ }^{77}$ Furthermore, other experiments $s^{60}$ and titration calculations ${ }^{33}$ suggest that the proton release complex of BR is not a specific residue but instead an excess of proton within an hydrogen-bond network involving at least two internal water molecules. From our calculations we find that at least one proton is bound to the proton release complex in the physiological $\mathrm{pH}$ range. The titrations of these two glutamic acid residues located near the extracellular region are slightly influenced by the $\mathrm{pH}$ of the cytoplasm $\left(\mathrm{pH}_{\mathrm{CP}}\right.$ above $\left.8-10\right)$.

In summary, six titratable sites in BR (D85, D96, D115, E194, E204, and the Schiff base) show a titration behavior that is influenced by the $\mathrm{pH}$ gradient across the membrane. Their titration curves are slightly influenced by the local 
conformational variability, as shown by the three ground-state structures that we studied here. The main effect of the mobile ions in the solvent is to shield the electrostatic interactions between the titratable residues, which results in only slight changes of the titration curves. Even though the ionic strength is felt by internal residues such as D85 and the Schiff base as a result of the longrange electrostatic coupling, its effect is minor for those residues. The residues that are influenced by the transmembrane $\mathrm{pH}$ gradient participate directly or indirectly in the active proton transfer. ${ }^{12}$ Since no titration experiments under a $\mathrm{pH}$ gradient have been reported for BR so far, our theoretical results predict that a $\mathrm{pH}$ gradient influences significantly the functional residues of the protein. In particular, the first proton transfer step in the photocycle, where the Schiff base donates its proton to D85 (BR to M transition), is likely to be regulated by the $\mathrm{pH}$ gradient across the membrane, as observed experimentally. ${ }^{78}$ Future titration experiments accounting for the influence of the $\mathrm{pH}$ gradient on $\mathrm{BR}$ are highly desirable to confirm our predictions.

\section{The structural basis of the back-pressure effect}

At a certain level, the transmembrane $\mathrm{pH}$ gradient generated by BR inhibits further proton pumping. ${ }^{2}$ This phenomenon is known as the back-pressure effect. The influence of the transmembrane $\mathrm{pH}$ gradient has been studied on liposomes, in which BR pumps protons from the inner lumen of the vesicle to the external medium. ${ }^{79}$ Based on these measurements, it was concluded that the maximal $\mathrm{pH}$ gradient that $\mathrm{BR}$ can generate is four $\mathrm{pH}$ units and a diagram of the proton pumping active region of BR was derived. This diagram is depicted by dotted lines in Figure 6, which shows the protonation probability of D85 and D115 as well as the correlation between their protonation probabilities as a function of $\mathrm{pH}_{\mathrm{CP}}$ and $\mathrm{pH}_{\mathrm{EC}}$. The proton pumping active region is delimited by the $\mathrm{pH}_{\mathrm{EC}}=\mathrm{pH}_{\mathrm{CP}}$ diagonal, a line parallel with the diagonal but shifted by four $\mathrm{pH}$ units below the diagonal, a line at $\mathrm{pH}_{\mathrm{EC}} \approx 2.5$ parallel with the $\mathrm{pH}_{\mathrm{CP}}$-axis, and a line at $\mathrm{pH}_{\mathrm{CP}} \approx 10$ parallel with the $\mathrm{pH}_{\mathrm{EC}}$-axis. The line at $\mathrm{pH}_{\mathrm{EC}} \approx 2.5$ was identified with the $\mathrm{p} K_{1 / 2}$ value of $\mathrm{D} 85$. The proton pumping activity above the diagonal $\left(\mathrm{pH}_{\mathrm{EC}}>\right.$ $\mathrm{pH}_{\mathrm{CP}}$ ) cannot be investigated with this kind of experiment because the measurements always starts from the situation where $\mathrm{pH}_{\mathrm{CP}}=\mathrm{pH}_{\mathrm{EC}}$, i.e. at the diagonal. Proton pumping transfers protons from the inner of the liposome $\left(\mathrm{pH}_{\mathrm{CP}}\right)$ to the external medium $\left(\mathrm{pH}_{\mathrm{EC}}\right)$ and thus leads to an acidification of the external medium and an alkalization of the liposome interior $\left(\mathrm{pH}_{\mathrm{EC}}<\mathrm{pH}_{\mathrm{CP}}\right)$.

From our titration calculations under the influence of a $\mathrm{pH}$ gradient, we can rationalize the proton pumping active region of Figure 6 and relate this functional feature to structural informations. For $\mathrm{pH}_{\mathrm{EC}}<2.5$ and $\mathrm{pH}_{\mathrm{CP}}<6.5$, D85 becomes protonated and cannot function as the proton acceptor in the first proton transfer from the Schiff base (Figure 6). This explanation was already found from previous studies. ${ }^{79}$ When $\mathrm{pH}_{\mathrm{CP}}$ rises above 6.5 , the $\mathrm{p} K_{1 / 2}$ of $\mathrm{D} 85$ shifts upwards. Therefore, already at higher $\mathrm{pH}_{\mathrm{EC}}, \mathrm{D} 85$ cannot accept a proton from the Schiff base anymore. The $\mathrm{p} K_{1 / 2}$ shift of D85 is due to the strong electrostatic interaction of about $4 \mathrm{kcal} / \mathrm{mol}$ with D115 (Figure 2). The strong interaction between these two residues can also be seen from the anticorrelation of -0.23 in Figure 4, which is close to the maximal possible value of -0.25 . Since D115 most likely receives its proton from the $\mathrm{CP}$ region and D85 from the $\mathrm{EC}$ region, their interaction leads to a mutual shift of the $\mathrm{p} K_{1 / 2}$ value parallel with the diagonal of Figure 6 . This shift roughly coincides with the line parallel with the diagonal delimiting the proton pumping active region. At $\mathrm{pH}_{\mathrm{CP}}>10$, D115 becomes deprotonated and stabilizes the protonated Schiff base by $5.6 \mathrm{kcal} /$ mol. This stabilization of the proton on the Schiff base should occur not only in the ground-state but
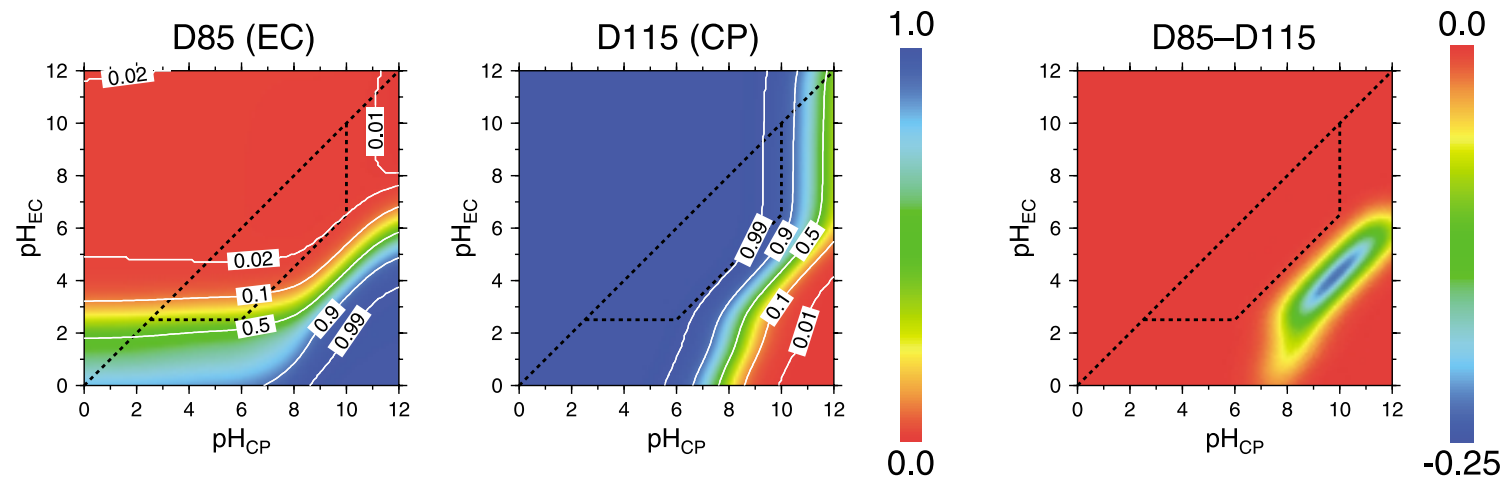

Figure 6. Two-dimensional titration curves of D85 and D115 in the 1C3W model (left and middle), and correlation between the protonation states of these residues (right). The area delimited by the dotted lines represents the $\mathrm{pH}$ region in which BR can pump protons according to Kouyama et al. ${ }^{79}$ D85 and D115 start titrating in the $\mathrm{pH}$ regions where BR is inhibited by the back-pressure effect. The plot on the right-hand side shows a strong anti-correlation between these two residues, indicating that the deprotonation of D115 favors the protonation of D85. 
also in the next intermediates along the BR photocycle. Thus, deprotonating $\mathrm{D} 115$ at $\mathrm{pH}_{\mathrm{CP}}>10$ is expected to stop the photocycle from functioning.

Taken together, these experimental data and our computational results suggest a possible role of D115 in the regulation of the proton pumping function of $\mathrm{BR}$ under high $\mathrm{pH}$ gradients. We propose that the strong electrostatic interactions between D85, D115, and the Schiff base as well as the interplay of their protonation states are responsible for the back-pressure effect on BR when a high $\mathrm{pH}$ gradient is reached.

\section{Conclusion}

Here, we investigated the effect of a transmembrane $\mathrm{pH}$ gradient on the protonation probabilities of BR. For this purpose, we introduced a theoretical framework to account for the effect of the $\mathrm{pH}$ gradient on the titration calculations of transmembrane proteins. In a transmembrane protein, the residues connected to different sides of the membrane may be exposed to different proton concentrations. As a consequence of the electrostatic interactions between these residues, the titration curves can become highly irregular and may depend on the $\mathrm{pH}$ at the two sides of the membrane. The titratable residues exchange protons with the bulk solvent either directly or, in the case of buried residues, through an extensive hydrogen-bond network. The $\mathrm{pH}$ value felt by a particular buried residue thus depends on the hydrogen-bond network around this residue. By searching for proton transfer paths in the hydrogen-bond network of bacteriorhodopsin, most of the titratable residues could be uniquely connected to either the cytoplasmic or the extracellular region. None of the residues was connected to both sides of the membrane. This structural feature is required for a protein which performs a vectorial proton transfer, i.e. there are two separate parts of the hydrogen-bond network in the protein: one at the cytoplasmic side of the protein, and another at its extracellular side. ${ }^{12,47}$

The protonation probability of 6 of the 39 titratable sites of bacteriorhodopsin depends on the $\mathrm{pH}$ at the two sides of the membrane. These sites are the residues D85, D96, D115, E194, E204, and the Schiff base. They are directly or indirectly involved in the proton transfer during the photocycle of BR. ${ }^{12}$ Thus, the $\mathrm{pH}$ gradient that BR generates influences the titratable sites located deeply in the protein core as well as the residues involved in the proton release to the extracellular region and the proton uptake from the cytoplasm.

The back-pressure effect of BR, which can be interpreted as a feedback inhibition of the generated transmembrane $\mathrm{pH}$ gradient on proton pumping, prevents over-acidification of the external medium. This functional feature of BR can be of physiological importance when $H$. salinarum lives in dense colonies: making the local environment become too acidic would be hazardous for the cell. According to our calculations, the electrostatic interactions between D85, D115, and the Schiff base and the interplay of their protonation states provide the structural basis for the back-pressure effect. Our calculations shed new light on the role of D115. The function of this residue has not been fully clarified yet. We propose that D115 senses the $\mathrm{pH}$ on the cytoplasmic side of the membrane and transmits this information to D85 and the Schiff base of BR, two key sites involved in the proton transfer mechanism of BR. This information is transmitted over long distances via long-range electrostatic interactions. Since many biological membranes separate compartments that have different $\mathrm{pH}$, the situation described here is important to understand the function of transmembrane proteins in general.

\section{Methods}

\section{Preparation of three ground-state BR structures}

Three high-resolution X-ray structures of ground-state BR were used as starting models for all calculations. The first two structures with PDB codes $1 \mathrm{C}^{2} \mathrm{~W}^{57}$ and $1 \mathrm{KGB}^{58}$ were solved at $1.55 \AA$ and $1.65 \AA$, respectively, from crystals grown with the cubic lipid phase method. ${ }^{80}$ The third structure with PDB code 1KME was solved at $2.0 \AA$ from crystals obtained with the bicelle crystallization method. ${ }^{59}$ This model contains two upside-down monomers in the unit cell that show no structural deviation after superimposing ${ }^{81}$ their $C^{\alpha}$ atoms (the allatom RMSD value is $<10^{-3} \AA$ ). The second monomer was thus discarded.

The structures 1C3W and 1KGB lack the intracellular EF loop (residues 155-162). We therefore took the EF loop coordinates from the $1 \mathrm{QHJ}$ structure ${ }^{45}$ after superimposing its $\mathrm{C}^{\alpha}$ atoms to those of $1 \mathrm{C} 3 \mathrm{~W}$ and of $1 \mathrm{KGB}$, respectively. The side-chain of R175 clashed with T157 once the EF loop was added. In the 1QHJ model, R175 adopts a different conformation which prevents those bad contacts. Moreover, this conformation allows for hydrogen bonding between R175 and both T157 and N176. Hence, the conformation of the R175 residue was taken from $1 \mathrm{QHJ}$. The EF loop and its flanking residues (150-176) were then relaxed with 500 steps of steepest descents minimization followed by 500 steps of adopted basis Newton-Raphson minimization. All other atomic coordinates were kept fixed. Positional harmonic constraints were used in order to limit the coordinate changes. A force constant of $1 \mathrm{kcal} \mathrm{mol}^{-1} \AA^{-2}$ restrained all atoms of the added EF loop and the nearby M163 residue. Higher restraints were applied to the backbone and side-chain atoms (5 and $2 \mathrm{kcal} \mathrm{mol}^{-1} \AA^{-2}$, respectively) of the residues flanking the EF loop (150-154 and 164-176). The side chains of R175 as well as K172 were restrained with a weak force constant $\left(0.1 \mathrm{kcal} \mathrm{mol}^{-1} \AA^{-2}\right)$. The energy minimizations were done using the program CHARMM. ${ }^{82}$

All lipids and crystallographic water molecules were removed from the structures. The water molecules were modelled with a high dielectric constant and the membrane environment with a low dielectric region around the protein (see below). Neutral blocking groups were added to the main-chain termini (acetylated $\mathrm{N}$ 
terminus for the residue $\mathrm{T} 5$, and $N$-methylamide $\mathrm{C}$ terminus for G131), since the flanking residues are not resolved in any of the known crystal structures of BR. Hydrogen positions were constructed with the HBUILD procedure $^{83}$ in CHARMM using the CHARMM22 parameter set ${ }^{84}$ and subsequently optimized with 100 steps of adopted basis Newton-Raphson minimization.

\section{Hydrogen-bond network and residue connectivity to the bulk}

The following part describes the methods that we used to calculate the side-chain-side-chain hydrogen bonds; to identify the protein internal cavities and the solvent accessibilities of the residues which form additional hydrogen bonds; and to search the hydrogenbond network by graph-theoretical methods in order to connect each titratable residue to either the $\mathrm{CP}$ or the EC region. Those calculations were performed with software developed for the present study unless noted otherwise.

Hydrogen bonds were calculated by first constructing hydrogen atom positions with standard geometrical parameters as taken from the CHARMM22 force field. ${ }^{84} \mathrm{We}$ used only geometrical criteria to decide whether a proton donor/acceptor pair forms a hydrogen bond. These criteria are detailed in Figure 7. They are similar to, though not identical with, those defined in other programs such as HBplus ${ }^{85}$ and HBexplore. ${ }^{86}$ We used the following values for atomic distances and angles: $d_{1} \leq 2.5 \mathrm{~A}, d_{2} \leq 4.0 \mathrm{~A}, \alpha \geq 120^{\circ}, \epsilon \leq 60^{\circ}$, and $\zeta \leq 60^{\circ}$. They are relatively loose to implicitly allow for local structural flexibility. All hydrogen bonds involving backbone atoms were discarded, since only side-chain
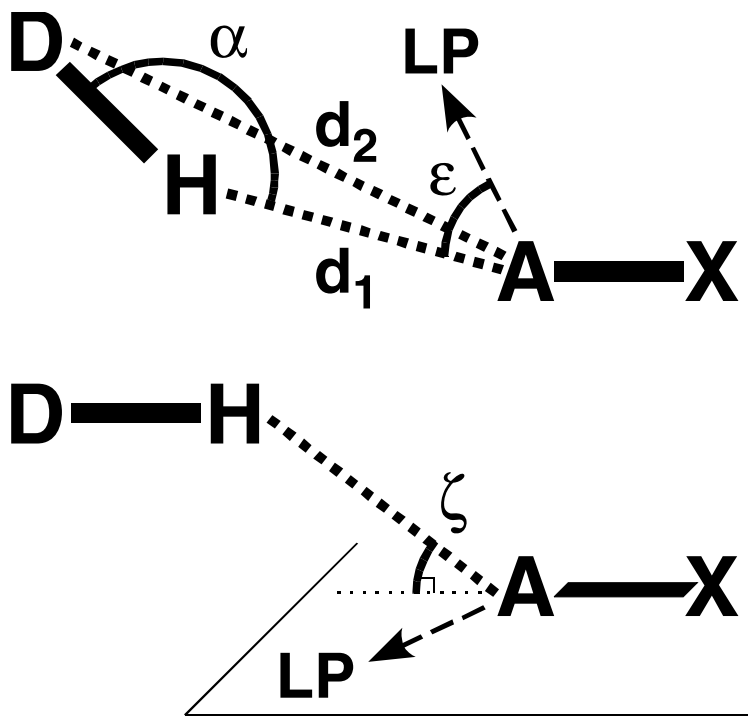

Figure 7. Definition of the hydrogen-bond criteria. Donor atom (D), acceptor atom $(\mathrm{A})$, hydrogen atom $(\mathrm{H})$, and lone pair (LP) for acceptors in $\mathrm{sp} 2$ configuration bonded to atom $(X) . d_{1}$, distance between the proton $H$ and the acceptor A. $d_{2}$, distance between the donor D and the acceptor A. $\alpha$, angle formed by the D-H..A triad. $\epsilon$, angle involving the proton $\mathrm{H}$, the acceptor $\mathrm{A}$, and any of the acceptor lone-pairs LP when they exist. $\zeta$, angle of the hydrogen bond with respect to the plane $\mathrm{LP}, \mathrm{A}, \mathrm{X}$ for an sp2 acceptor (or to the plane $\mathrm{X}^{\prime}, \mathrm{D}, \mathrm{H}$ for an sp2 donor). hydrogen bonds are relevant for proton transfer. The hydrogen-bond network can be represented as a mathematical graph made of atoms (nodes) connected via hydrogen bonds (vectorial arcs) directed from the donor towards the acceptor atom.

Protein internal cavities were identified using a 3Dgrid, which initially was big enough to hold the whole protein (Figure 8a, "coarse" grid). All crystallographic water molecules were removed from the structure, and atomic radii of the solute were expanded by the radius of a probe sphere which represents a water molecule. First, the solvent-accessible volume of the protein was

a)

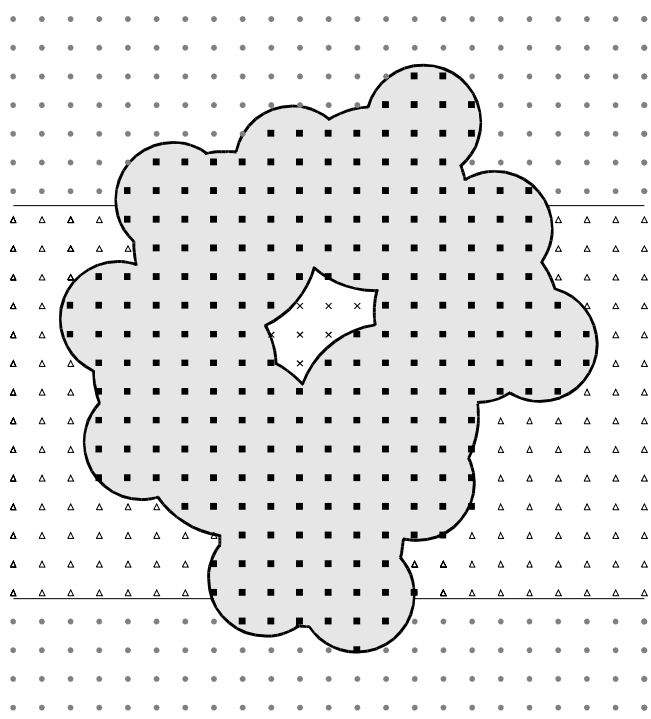

b)

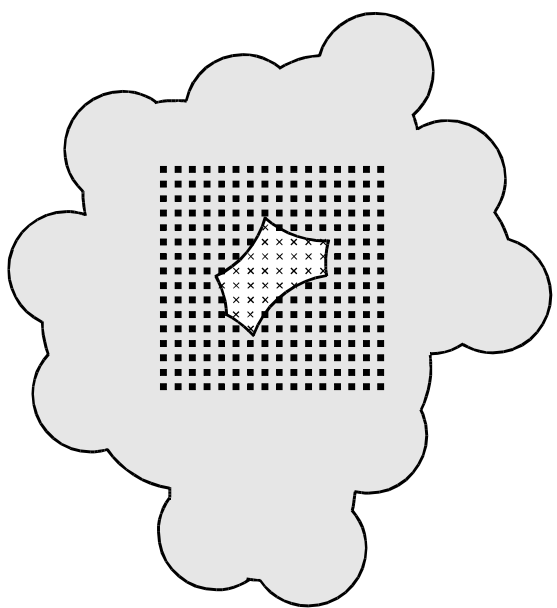

Figure 8. Grid searching for molecular cavities and linkage with hydrogen bonds. An arbitrary membrane protein is represented in $2 \mathrm{D}$ by its solvent-accessible surface (bold arcs). (a) A coarse grid is surrounding the molecule. Filled squares are grid points that belong to the interior of the solute (the volume contained within its solvent-accessible surface, in light gray). Gray dots are grid points located in the solvent. Open triangles denote grid points located in the membrane delimited by the thin horizontal lines. Crosses are the remaining grid points contained in molecular cavities. (b) Cavity refinement with individual grids. A finer grid is used to refine the cavities obtained with the coarse grid, and the lining polar atoms are identified. 
mapped to the grid, i.e. all grid points in the expanded atoms were assigned to the solute. Second, starting from the grid corners and using a simple linear scanning, all grid points outside of the protein were assigned to the solvent or to the membrane environment. Third, the remaining unassigned grid points, which thus belong to protein internal cavities, were discriminated using a flood-filling technique ${ }^{87}$ that finds all neighbors to any grid point located in a cavity. To allow for very fine grids, the flood-filling technique was implemented with a non-recursive algorithm. A refinement procedure then sampled again each cavity with a finer and smaller grid centered at the cavity (Figure 8b, "fine" grid). The volume of the refined cavities was calculated and their lining residues were identified. At this stage the refined cavities were assumed to contain water molecules that can conduct protons. Hydrogen bonds were added between the cavity and all surrounding hydrogen-bond donors and acceptors. No geometrical criteria were considered here. Finally, each solvent-accessible hydrogenbond donor or acceptor was connected to either the EC or the $\mathrm{CP}$ side. Coarse cavities were obtained using a grid spacing of $0.1 \AA$. The cavity refinement was performed with a grid spacing of $0.05 \AA$. The probe radius of $1.4 \AA$ was reduced by twice the grid spacing in order to compensate for the use of a discrete grid. The protein and retinal atomic radii were $1.0 \AA$ for $\mathrm{H}$ atoms, $1.55 \AA$ for $\mathrm{N}, 1.7 \AA$ for $\mathrm{C}, 1.5 \AA$ for $\mathrm{O}$, and $1.8 \AA$ for $\mathrm{S}$.

The search for solvent connectivity paths was conducted for each of the 39 titratable residues in the three BR models using Dijkstra's algorithm. ${ }^{88}$ The titratable residues which could not be connected to the EC or to the $\mathrm{CP}$ region were connected according to experimental data taken from the literature (see Results). No residue was found to be connected to both the EC and $\mathrm{CP}$ regions, which is consistent with a vectorial proton transfer.

\section{Model construction of the membrane environment}

In order to model the low dielectric region of the membrane, the BR structures were embedded in a ring of dummy atoms which represents the hydrophobic part of the membrane lipids (Figure 9). The ring resembles a micelle of lipids surrounding the protein. This representation of the membrane offers several advantages over the infinite low-dielectric slab model. ${ }^{27}$ The first advantage is that we can include the ionic strength in the calculation of the electrostatic energy of the system. Considering ionic strength is important for $\mathrm{BR}$, since the optimal salt concentration for $H$. salinarum growth is $4-5 \mathrm{M} \mathrm{NaCl}$ (see, e.g. Madigan \& Oren's review). ${ }^{65}$ The second advantage is that all protein cavities are filled with a high dielectric medium. In the infinite slab method, a cylinder is used to define the region, which might contain protein cavities, i.e. highdielectric regions inside the membrane part of the protein. The regions in the cylinder volume which are not occupied by the protein are treated as high-dielectric regions. Thus, if the cylinder is chosen too big, the highdielectric region expands into the membrane. If it is chosen too small, a low-dielectric medium fills the cavities lying outside the cylinder. Consequently, the infinite slab model tends to be replaced by alternatives that are equivalent in effect, such as the dummy atom model described below or the models proposed recently in other theoretical studies of BR. ${ }^{34,35}$

The membrane ring of thickness $l$ was constructed as a)

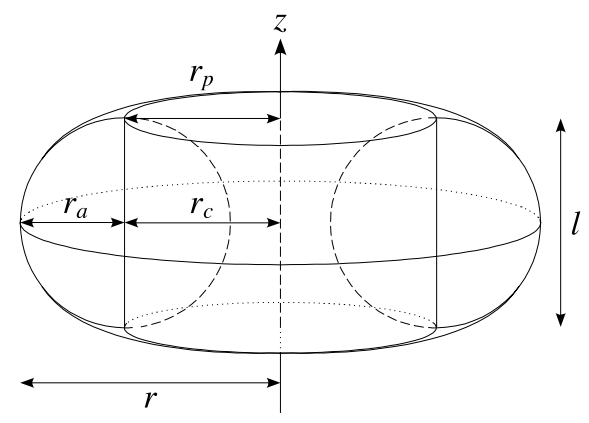

b)

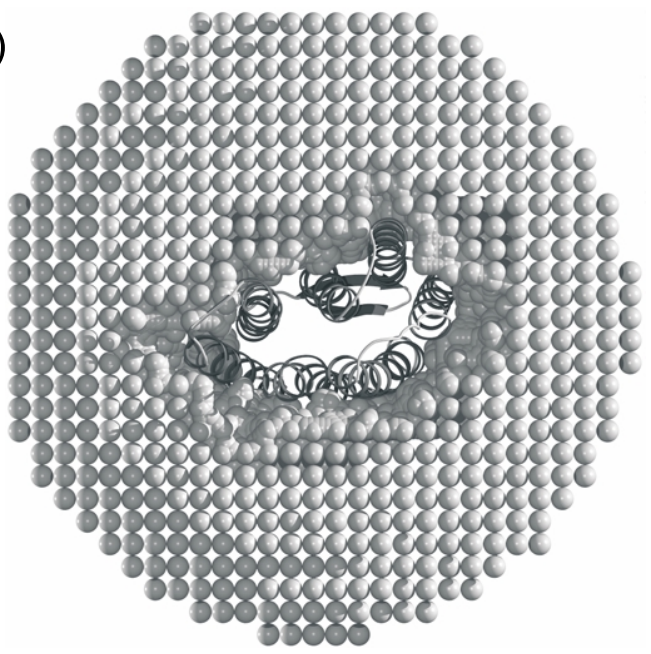

c)

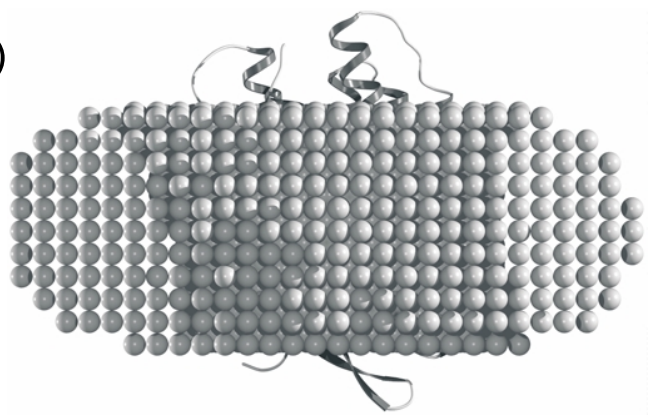

Figure 9. Bacteriorhodopsin in a modelled membrane environment. The membrane model is constructed with uncharged dummy atoms that fill the volume occupied by the hydrophobic tails of the lipids. The density of the dummy atoms increases along the protein surface to avoid creating artificial high-dielectric cavities. (a) The membrane ring is contained within the union of a cylinder (radius $r_{\mathrm{p}}$ ) and a torus (radius $r$ ) aligned along the $z$-axis (normal to the membrane plane). (b) BR and the membrane ring as viewed from the cytoplasm. (c) View along the membrane plane; cytoplasm is on top.

follows. The maximum radius $r_{\mathrm{p}}$ of the protein within the membrane region was determined (Figure 9a). A torus was then placed around the cylinder defined by $r_{\mathrm{p}}$ and $l$, such that $r_{\mathrm{c}}=r_{\mathrm{p}}$ and $r_{\mathrm{a}}=l / 2$, where $r_{\mathrm{c}}$ is the radius from the center of the torus hole to the center of the torus tube, and $r_{\mathrm{a}}$ is the radius of the torus tube. The outer radius of the torus $r=r_{\mathrm{c}}+r_{\mathrm{a}}$ defines a bounding-box of size $2 r \times 2 r \times l$. The construction of the ring starts by filling the space contained in this box at a regular interval of $3 \AA$, and placing dummy atoms of 
radius $r_{\mathrm{d}}=1.5 \AA$. The dummy atoms contact each other in a close-packed, face-centered array fashion. The $3 \AA$ interval is small enough that a water probe sphere of $1.4 \AA$ cannot lie in between the dummy atoms (the largest probe sphere that can fit has a radius of $\left.(\sqrt{3}-1) r_{\mathrm{d}} \sim 1.1 \AA\right)$. A dummy atom was retained if its position lay within the union of the torus and the cylinder but not within the volume of the protein and its internal cavities (Figure 9a and b). The volume occupied by the protein and its cavities was obtained using our cavity detection method (Figure 8a). Since the membrane construction may create artificial cavities between the dummy atoms and the protein surface, an adaptive subsampling of the dummy atom locations was performed near the protein surface. The density of dummy atoms was thus higher near the protein surface to adapt its shape (Figure 9b and c). Overall, the construction procedure led to a model of the membrane hydrophobic region that mimics a micelle around the protein.

BR structures were oriented such that the membrane lies in the $(x, y)$ plane by superimposing the 1KGB and $1 \mathrm{KME}$ models to $1 \mathrm{C} 3 \mathrm{~W}$, in which the crystallographic $a / b$ plane is equivalent to purple membrane sheets. ${ }^{57}$ The membrane boundaries along the $z$-axis (and thus its thickness $l$ ) were obtained by superimposing several X-ray structures of ground-state BR $\left(1 \mathrm{C} 3 \mathrm{~W},{ }^{57} 1 \mathrm{KGB},{ }^{58}\right.$ $1 \mathrm{C} 8 \mathrm{R}$ and $1 \mathrm{C}^{2} \mathrm{~S}^{89} 1 \mathrm{~F} 4 \mathrm{Z}$ and $1 \mathrm{~F} 50^{90}$ ) that contain lipid chains, and averaging the $\mathrm{z}$-coordinates of the lipid $C_{(11)}$ and $C_{(41)}$ atoms. This averaging gave a membrane extending in the range $-12.2-18.5 \mathrm{~A}$ along the $z$-axis relative to the $1 \mathrm{C} 3 \mathrm{~W}$ model. The corresponding thickness, about $31 \AA$, is compatible with experimental measurements ${ }^{56}$ when polar heads (about $5 \AA$ ) are excluded. Visual inspection also showed that the overall membrane location fits well the protein temperature factors in the used models. A membrane ring was constructed for each of the three BR models in order to account for structural variations.

\section{Continuum electrostatics calculations}

The intrinsic $\mathrm{p} K_{\mathrm{a}}$ value $\left(\mathrm{p} K_{\mathrm{a}, i}^{\mathrm{intr}}\right)$ for each titratable site of $\mathrm{BR}$ and the interaction energies between them (the $W_{i j}$ site-site interactions) in equation (4) were obtained by continuum electrostatics calculations. ${ }^{24}$ The PoissonBoltzmann equation was solved by a finite-difference method $^{91}$ using the MEAD program suite. ${ }^{27,92}$ The membrane environment of BR was modeled as described above with a low-dielectric uncharged ring surrounding the protein, so that both membrane and ionic strength effects are included.

All aspartic acid residues, glutamic acid residues, lysine, arginine, and tyrosine residues as well as the retinal Schiff base were considered as protonatable sites (BR has no histidine residue). Crystallographic water molecules were not included in these calculations. Instead, internal water molecules were treated as a high-dielectric medium filling the protein cavities. Atomic partial charges for standard amino acid groups were taken from the CHARMM22 parameter set. ${ }^{84}$ The charges of the retinal Schiff base were derived from a density functional calculation with the $\mathrm{VWM}^{93}$ and $\mathrm{PW}^{94}$ functionals, and using the program $\mathrm{ADF}^{95}$ (Table 3). The electrostatic potentials obtained from these calculations were fitted using the CHELPG algorithm $^{96}$ combined with a singular value decomposition. ${ }^{97}$ The remaining charges for the retinal were taken from Baudry et al. ${ }^{98}$ The $\mathrm{p} K_{\mathrm{a}}$ values of the
Table 3. Atomic partial charges as determined by density functional calculations for the protonated and deprotonated forms of the retinal Schiff base

\begin{tabular}{lrr}
\hline Atom & Protonated & Deprotonated \\
\hline C11 & -0.03391 & -0.23446 \\
H11 & 0.20455 & 0.20970 \\
C12 & -0.27954 & -0.27113 \\
H12 & 0.21729 & 0.19015 \\
C13 & 0.34170 & 0.36220 \\
C20 & -0.28589 & -0.31866 \\
H20A & 0.12636 & 0.10206 \\
H20B & 0.12636 & 0.10206 \\
H20C & 0.12636 & 0.10206 \\
C14 & -0.50964 & -0.62811 \\
H14 & 0.24913 & 0.21799 \\
C15 & 0.15469 & 0.34992 \\
H15 & 0.19675 & 0.03840 \\
NZ & -0.19133 & -0.30054 \\
HZ & 0.33665 & 0.00000 \\
CE & -0.15774 & -0.19392 \\
HE1 & 0.19361 & 0.14129 \\
HE2 & 0.18459 & 0.13100 \\
\hline
\end{tabular}

model compounds were taken from the literature. ${ }^{26,33,99}$ The dielectric constant of the protein and membrane interiors was set to 4 , and that of the solvent was set to 80 . The dielectric boundary between solute and solvent was calculated using a water probe sphere of $1.4 \AA$ radius and the atomic radii given above. The ionic strength was set to $1 \mathrm{M}$ in order to match, on average, various experimental conditions for BR titrations. The thickness of the ion exclusion layer was set to $2.0 \AA$. The ionic strength was zero within the protein cavities, since no internal cavity was found when using a probe sphere of $2.0 \AA$ radius.

Continuum electrostatics calculations were performed using the focusing technique ${ }^{91}$ in three steps due to the size of the system which includes the large membrane ring. The biggest grid was placed at the geometric center of the system. The resolution of this initial coarse grid was $1.0 \AA$ and the distance between the grid boundaries and the membrane ring or the protein surface was at least $10 \AA$. Because of some geometrical differences, we used $101^{3}$ grid points for $1 \mathrm{C} 3 \mathrm{~W}$ and $1 \mathrm{KGB}$, and $121^{3}$ grid points for 1KME. In the second focusing step, we used a finer grid with $81^{3}$ points and a grid spacing of $0.5 \AA$. In the third step, the finest grid was defined with $101^{3}$ points and a grid spacing of $0.2 \AA$. The latter two grids were centered at the titratable site. A similar procedure was used for the model compound, with all grids centered at the titratable site. These grids had dimensions of $81^{3}, 81^{3}$, and $101^{3}$, and grid spacings of $1.0 \AA, 0.5 \AA$, and $0.2 \AA$, respectively.

\section{Calculation of the titration profile}

In order to calculate the protonation probabilities of all titratable sites in the BR protein, we used a Monte Carlo approach (MC) similar to that implemented in the MCTI $^{41}$ and Karlsberg ${ }^{42,100,101}$ programs. The elementary MC move is the attempt to change the protonation state of a randomly chosen titratable site. The Metropolis criterion is evaluated at the given temperature to accept or reject the move. The efficiency of the sampling is increased by a special treatment of pairs (double moves ${ }^{41}$ ) or triplets (triple moves ${ }^{102}$ ) of titratable sites that interact by more than a certain energy threshold. In 
the case of a double (resp. triple) move, the protonation state of the two (resp. three) titratable sites is changed before the Metropolis criterion is evaluated. We implemented the MC method with double and triple moves in a program that allows us to calculate the protonation probabilities as a function of two $\mathrm{pH}$ values.

Two-dimensional titration profiles were calculated for a wide range of $\mathrm{pH}$ values. The intracellular $\mathrm{pH}\left(\mathrm{pH}_{\mathrm{CP}}\right)$ and extracellular $\mathrm{pH}\left(\mathrm{pH}_{\mathrm{EC}}\right)$ were sampled from $\mathrm{pH} 0$ to $\mathrm{pH} 16$ by increments of $0.1 \mathrm{pH}$ unit, which results in 25,961 evaluations of the protonation probability of each titratable site. The temperature was set to $293 \mathrm{~K}$. The coupling threshold defining the pairs of titratable sites for double moves was set to $2 \mathrm{p} K_{\mathrm{a}}$ units. The coupling threshold for triple moves was set to $3 p K_{a}$ units. In all, 30,000 MC scans were performed, where one MC scan comprises as many $\mathrm{MC}$ moves as titratable sites, pairs and triplets are present in the molecule. At each pair of $\mathrm{pH}$ values $\left(\mathrm{pH}_{\mathrm{EC}}, \mathrm{pH}_{\mathrm{CP}}\right)$, a randomly chosen initial state vector was equilibrated with $100 \mathrm{MC}$ scans.

\section{Acknowledgements}

This work was supported by an Emmy-Noether grant (UL 174/2-1,2) and the retinal protein Forschergruppe 490 (UL 174/4-1) of the Deutsche Forschungsgemeinschaft. Some of the calculations were done on the HELICS-supercomputer at the IWR (University of Heidelberg). We thank Professor Donald Bashford for providing his program MEAD, and Professor Jeremy C. Smith, Nicoleta Bondar, Edda Kloppmann, and Dr Andreea Gruia for helpful discussion.

\section{References}

1. Westerhoff, H. V., Scholte, B. J. \& Hellingwerf, K. J. (1979). Bacteriorhodopsin in liposomes. I. A description using irreversible thermodynamics. Biochim. Biophys. Acta, 547, 544-560.

2. Westerhoff, H. V. \& Dancsházy, Z. (1984). Keeping a light-driven proton pump under control. Trends Biochem. Sci. 9, 112-117.

3. Hellingwerf, K. J., Schuurmans, J. J. \& Westerhoff, H. V. (1978). Demonstration of coupling between the protonmotive force across bacteriorhodopsin and the flow through its photochemical cycle. FEBS Letters, 92, 181-186.

4. Hellingwerf, K. J., Arents, J. C., Scholte, B. J. \& Westerhoff, H. V. (1979). Bacteriorhodopsin in liposomes. II. Experimental evidence in support of a theoretical model. Biochim. Biophys. Acta, 547, 561-582.

5. Arents, J. C., van Dekken, H., Hellingwerf, K. J. \& Westerhoff, H. V. (1981). Linear relations between proton current and $\mathrm{pH}$ gradient in bacteriorhodopsin liposomes. Biochemistry, 20, 5114-5123.

6. Dubrovskii, V., Balashov, S. P., Sineshchekov, O., Chekulaeva, L. N. \& Litvin, F. F. (1982). Lightinduced changes in quantum yields of the photochemical cycle of conversion of bacteriorhodopsin and transmembrane proton transfer in cells of halobacterium halobium. Biokhimiia, 47, 1230-1240.

7. Kouyama, T., Nasuda-Kouyama, A. \& Ikegami, A.
(1987). Bacteriorhodopsin is a powerful light-driven proton pump. Biophys. J. 51, 839-841.

8. Kouyama, T. \& Nasuda-Kouyama, A. (1989). Turnover rate of the proton pumping cycle of bacteriorhodopsin: $\mathrm{pH}$ and light-intensity dependences. Biochemistry, 28, 5963-5970.

9. Nasuda-Kouyama, A., Fukuda, K., Iio, T. \& Kouyama, T. (1990). Effect of a light-induced $\mathrm{pH}$ gradient on purple-to-blue and purple-to-red transitions of bacteriorhodopsin. Biochemistry, 29, 6778-6788.

10. Katsu, T., Nakagawa, H., Kanamori, T., Kamo, N. \& Tsuchiya, T. (2001). Ion-selective electrode for transmembrane $\mathrm{pH}$ difference measurements. Anal. Chem. 73, 1849-1854.

11. Váró, G. \& Lanyi, J. K. (1989). Photoreactions of bacteriorhodopsin at acid $\mathrm{pH}$. Biophys. J. 56, 1143-1151.

12. Balashov, S. P. (2000). Protonation reactions and their coupling in bacteriorhodopsin. Biochim. Biophys. Acta, 1460, 75-94.

13. Wang, J. \& El-Sayed, M. A. (2000). The effect of protein conformation change from $\alpha_{\text {II }}$ to $\alpha_{\text {I }}$ on the bacteriorhodopsin photocycle. Biophys. J. 78, 2031-2036.

14. Groma, G. I., Kelemen, L., Kulcsár, A., Lakatos, M. \& Váró, G. (2001). Photocycle of dried acid purple form of bacteriorhodopsin. Biophys. J. 81, 3432-3441.

15. Klink, B. U., Winter, R., Engelhard, M. \& Chizhov, I. (2002). Pressure dependence of the photocycle kinetics of bacteriorhodopsin. Biophys. J. 83, 3490-3498.

16. Blok, M. C., Hellingwerf, K. J. \& van Dam, K. (1977). Reconstitution of bacteriorhodopsin in a millipore filter system. FEBS Letters, 76, 45-50.

17. Hellingwerf, K. J., Scholte, B. J. \& van Dam, K. (1978). Bacteriorhodopsin vesicles. An outline of the requirements for light-dependent $\mathrm{H}^{+}$pumping. Biochim. Biophys. Acta, 513, 66-77.

18. Quintanilha, A. T. (1980). Control of the photocycle in bacteriorhodopsin by electrochemical gradients. FEBS Letters, 117, 8-12.

19. Rigaud, J. L., Bluzat, A. \& Buschlen, S. (1983). Incorporation of bacteriorhodopsin into large unilamellar liposomes by reverse phase evaporation. Biochem. Biophys. Res. Commun. 111, 373-382.

20. Muneyuki, E., Ikematsu, M. \& Yoshida, M. (1996). $\Delta \mu \mathrm{H}^{+}$dependency of proton translocation by bacteriorhodopsin and a stochastic energizationrelaxation channel model. J. Phys. Chem. 100, 19687-19691.

21. Kahya, N., Pecheur, E. I., de Boeij, W. P., Wiersma, D. A. \& Hoekstra, D. (2001). Reconstitution of membrane proteins into giant unilamellar vesicles via peptide-induced fusion. Biophys. J. 81, 1464-1474.

22. Michel, H. \& Oesterhelt, D. (1976). Light-induced changes of the $\mathrm{pH}$ gradient and the membrane potential in H. halobium. FEBS Letters, 65, 175-178.

23. Joshi, M. K., Bose, S. \& Hendler, R. W. (1999). Regulation of the bacteriorhodopsin photocycle and proton pumping in whole cells of Halobacterium salinarium. Biochemistry, 38, 8786-8793.

24. Bashford, D. \& Karplus, M. (1990). $\mathrm{p} K_{\mathrm{a}}$ s of ionizable groups in proteins: atomic detail from a continuum electrostatic model. Biochemistry, 29, 10219-10225.

25. Honig, B. \& Nicholls, A. (1995). Classical electrostatics in biology and chemistry. Science, 268, 1144-1149.

26. Ullmann, G. M. \& Knapp, E.-W. (1999). Electrostatic 
models for computing protonation and redox equilibria in proteins. Eur. Biophys. J. 28, 533-551.

27. Bashford, D. \& Gerwert, K. (1992). Electrostatic calculations of the $\mathrm{p} K_{\mathrm{a}}$ values of ionizable groups in bacteriorhodopsin. J. Mol. Biol. 224, 473-486.

28. Sampogna, R. V. \& Honig, B. (1994). Environmental effects on the protonation states of active site residues in bacteriorhodopsin. Biophys. J. 66, 1341-1352.

29. Engels, M., Gerwert, K. \& Bashford, D. (1995). Computational studies of the early intermediates of the bacteriorhodopsin photocycle. Biophys. Chem. 56, 95-104.

30. Sampogna, R. V. \& Honig, B. (1996). Electrostatic coupling between retinal isomerization and the ionization state of Glu-204: a general mechanism for proton release in bacteriorhodopsin. Biophys. J. 71, 1165-1171.

31. Sandberg, L. \& Edholm, O. (1997). $\mathrm{p} K_{\mathrm{a}}$ calculations along a bacteriorhodopsin molecular dynamics trajectory. Biophys. Chem. 65, 189-204.

32. Sandberg, L. \& Edholm, O. (1999). A fast and simple method to calculate protonation states in proteins. Proteins: Struct. Funct. Genet. 36, 474-483.

33. Spassov, V. Z., Luecke, H., Gerwert, K. \& Bashford, D. (2001). $p K_{a}$ calculations suggest storage of an excess proton in a hydrogen-bonded water network in bacteriorhodopsin. J. Mol. Biol. 312, 203-219.

34. Song, Y., Mao, J. \& Gunner, M. R. (2003). Calculation of proton transfers in bacteriorhodopsin bR and $M$ intermediates. Biochemistry, 42, 9875-9888.

35. Onufriev, A., Smondyrev, A. \& Bashford, D. (2003). Proton affinity changes driving unidirectional proton transport in the bacteriorhodopsin photocycle. J. Mol. Biol. 332, 1183-1193.

36. Ullmann, G. M. (2000). The coupling of protonation and reduction in proteins with multiple redox centers: theory, computational method, and application to cytochrome $c_{3}$. J. Phys. Chem. ser. B, 104, 6293-6301.

37. Onufriev, A., Case, D. A. \& Ullmann, G. M. (2001). A novel view on the $\mathrm{pH}$ titration of biomolecules. Biochemistry, 40, 3413-3419.

38. Ullmann, G. M., Noodleman, L. \& Case, D. A. (2002). Density functional calculation of the $\mathrm{p} K_{\mathrm{a}}$ values of the histidines coordinating one iron in the bovine Rieske iron-sulphur protein. J. Biol. Inorg. Chem. 7, 632-639.

39. Ullmann, G. M. (2003). Relations between protonation constants and titration curves in polyprotic acids: a critical view. J. Phys. Chem. ser. B, 107, 1263-1271.

40. You, T. J. \& Bashford, D. (1995). Conformation and hydrogen ion titration of proteins: a continuum electrostatic model with conformational flexibility. Biophys. J. 69, 1721-1733.

41. Beroza, P., Fredkin, D. R., Okamura, M. Y. \& Feher, G. (1991). Protonation of interacting residues in a protein by a Monte Carlo method: application to lysozyme and the photosynthetic reaction center. Proc. Natl Acad. Sci. USA, 88, 5804-5808.

42. Rabenstein, B., Ullmann, G. M. \& Knapp, E. W. (2000). Electron transfer between the quinones in the photosynthetic reaction center and its coupling to conformational changes. Biochemistry, 39, 10487-10496.

43. Roux, B. (1997). Influence of the membrane potential on the free energy of an intrinsic protein. Biophys. J. 73, 2980-2989.
44. Luecke, H., Richter, H.-T. \& Lanyi, J. K. (1998). Proton transfer pathways in bacteriorhodopsin at 2.3 angstrom resolution. Science, 280, 1934-1937.

45. Belrhali, H., Nollert, P., Royant, A., Menzel, C., Rosenbusch, J. P., Landau, E. M. \& Pebay-Peyroula, E. (1999). Protein, lipid and water organization in bacteriorhodopsin crystals: a molecular view of the purple membrane at $1.9 \AA$ resolution. Structure, 7, 909-917.

46. Kandori, H. (2000). Role of internal water molecules in bacteriorhodopsin. Biochim. Biophys. Acta, 1460, 177-191.

47. Grigorieff, N., Ceska, T. A., Downing, K. H., Baldwin, J. M. \& Henderson, R. (1996). Electroncrystallographic refinement of the structure of bacteriorhodopsin. J. Mol. Biol. 259, 393-421.

48. Brown, L. S., Dioumaev, A. K., Needleman, R. \& Lanyi, J. K. (1998). Local-access model for proton transfer in bacteriorhodopsin. Biochemistry, 37, 3982-3993.

49. Brown, L. S., Dioumaev, A. K., Needleman, R. \& Lanyi, J. K. (1998). Connectivity of the retinal schiff base to asp85 and asp96 during the bacteriorhodopsin photocycle: the local-access model. Biophys. J. 75, 1455-1465.

50. Herzfeld, J. \& Lansing, J. C. (2002). Magnetic resonance studies of the bacteriorhodopsin pump cycle. Annu. Rev. Biophys. Biomol. Struct. 31, 73-95.

51. Dencher, N. A., Sass, H. J. \& Büldt, G. (2000). Water and bacteriorhodopsin: structure, dynamics, and function. Biochim. Biophys. Acta, 1460, 192-203.

52. Luecke, H. (2000). Atomic resolution structures of bacteriorhodopsin photocycle intermediates: the role of discrete water molecules in the function of this light-driven ion pump. Biochim. Biophys. Acta, 1460, 133-156.

53. Finney, J. L. (1977). The organization and function of water in protein crystals. Phil. Trans. Roy. Soc. London, 278, 3-32.

54. Edsall, J. T. \& McKenzie, H. A. (1983). Water and proteins. II. The location and dynamics of water in protein systems and its relation to their stability and properties. Advan. Biophys. 16, 53-183.

55. Ernst, J. A., Clubb, R. T., Zhou, H. X., Gronenborn, A. M. \& Clore, G. M. (1995). Demonstration of positionally disordered water within a protein hydrophobic cavity by NMR. Science, 267, 1813-1817.

56. Kimura, Y., Vassylyev, D. G., Miyazawa, A., Kidera, A., Matsushima, M., Mitsuoka, K. et al. (1997). Surface of bacteriorhodopsin revealed by highresolution electron crystallography. Nature, 389, 206-211.

57. Luecke, H., Schobert, B., Richter, H.-T., Cartailler, J.-P. \& Lanyi, J. K. (1999). Structure of bacteriorhodopsin at $1.55 \AA$ resolution. J. Mol. Biol. 291, 899-911.

58. Facciotti, M. T., Rouhani, S., Burkard, F. T., Betancourt, F. M., Downing, K. H., Rose, R. B. et al. (2001). Structure of an early intermediate in the M-state phase of the bacteriorhodopsin photocycle. Biophys. J. 81, 3442-3455.

59. Faham, S. \& Bowie, J. U. (2002). Bicelle crystallization: a new method for crystallizing membrane proteins yields a monomeric bacteriorhodopsin structure. J. Mol. Biol. 316, 1-6.

60. Rammelsberg, R., Huhn, G., Luebben, M. \& Gerwert, K. (1998). Bacteriorhodopsin's intramolecular proton-release pathway consists of a 
hydrogen-bonded network. Biochemistry, 37, 5001-5009.

61. Heberle, J. (2000). Proton transfer reactions across bacteriorhodopsin and along the membrane. Biochim. Biophys. Acta, 1458, 135-147.

62. Metz, G., Siebert, F. \& Engelhard, M. (1992). Highresolution solid state ${ }^{13} \mathrm{C}$ NMR of bacteriorhodopsin: characterization of $\left[4-^{-13} \mathrm{C}\right]$ Asp resonances. Biochemistry, 31, 455-462.

63. Renthal, R., Gracia, N. \& Regalado, R. (2000). Water and carboxyl group environments in the dehydration blueshift of bacteriorhodopsin. Photochem. Photobiol. 72, 714-718.

64. Koyama, K. \& Miyasaka, T. (2000). The proton uptake channel of bacteriorhodopsin as studied by a photoelectrochemical method. Bioelectrochemistry, 53, 111-118.

65. Madigan, M. T. \& Oren, A. (1999). Thermophilic and halophilic extremophiles. Curr. Opin. Microbiol. 2, 265-269.

66. Balashov, S. P., Govindjee, R., Imasheva, E. S., Misra, S., Ebrey, T. G., Feng, Y. et al. (1995). The two $\mathrm{p} K_{\mathrm{a}}^{\prime} \mathrm{s}$ of aspartate-85 and control of thermal isomerization and proton release in the arginine- 82 to lysine mutant of bacteriorhodopsin. Biochemistry, $34,8820-8834$.

67. Balashov, S. P., Imasheva, E. S., Govindjee, R., Sheves, M. \& Ebrey, T. G. (1996). Evidence that aspartate-85 has a higher $\mathrm{p} K_{\mathrm{a}}$ in all-trans than in 13-cis bacteriorhodopsin. Biophys. J. 71, 1973-1984.

68. Balashov, S. P., Govindjee, R., Kono, M., Imasheva, E., Lukashev, E., Ebrey, T. G. et al. (1993). Effect of the arginine- 82 to alanine mutation in bacteriorhodopsin on dark adaptation, proton release, and the photochemical cycle. Biochemistry, 32, 10331-10343.

69. Brown, L. S., Bonet, L., Needleman, R. \& Lanyi, J. K. (1993). Estimated acid dissociation constants of the Schiff base, asp-85, and arg-82 during the bacteriorhodopsin photocycle. Biophys. J. 65, 124-130.

70. Jonas, R., Koutalos, Y. \& Ebrey, T. G. (1990). Purple membrane: surface charge density and the multiple effect of $\mathrm{pH}$ and cations. Photochem. Photobiol. 52, 1163-1177.

71. Druckmann, S., Ottolenghi, M., Pande, A., Pande, J. \& Callender, R. H. (1982). Acid-base equilibrium of the Schiff base in bacteriorhodopsin. Biochemistry, 21, 4953-4959.

72. Balashov, S. P., Govindjee, R. \& Ebrey, T. G. (1991). Red shift of the purple membrane absorption band and the deprotonation of tyrosine residues at high $\mathrm{pH}$ : origin of the parallel photocycles of transbacteriorhodopsin. Biophys. J. 60, 475-490.

73. Pfefferlé, J.-M., Maeda, A., Sasaki, J. \& Yoshizawa, T. (1991). Fourier transform infrared study of the $\mathrm{N}$ intermediate of bacteriorhodopsin. Biochemistry, $\mathbf{3 0}$ 6548-6556.

74. Hessling, B., Souvignier, G. \& Gerwert, K. (1993). A model-independent approach to assigning bacteriorhodopsin's intramolecular reactions to photocycle intermediates. Biophys. J. 65, 1929-1941.

75. Száraz, S., Oesterhelt, D. \& Ormos, P. (1994). pHinduced structural changes in bacteriorhodopsin studied by Fourier transform infrared spectroscopy. Biophys. J. 67, 1706-1712.

76. Brown, L. S., Sasaki, J., Kandori, H., Maeda, A., Needleman, R. \& Lanyi, J. K. (1995). Glutamic acid 204 is the terminal proton release group at the extra- cellular surface of bacteriorhodopsin. J. Biol. Chem. 270, 27122-27126.

77. Govindjee, R., Misra, S., Balashov, S. P., Ebrey, T., Crouch, R. \& Menick, D. (1996). Arginine-82 regulates the $\mathrm{p} K_{\mathrm{a}}$ of the group responsible for the light-driven proton release in bacteriorhodopsin. Biophys. J. 71, 1011-1023.

78. Geibel, S., Friedrich, T., Ormos, P., Wood, P. G. Nagel, G. \& Bamberg, E. (2001). The voltage-dependent proton pumping in bacteriorhodopsin is characterized by optoelectric behavior. Biophys. J. 81, 2059-2068.

79. Kouyama, T., Kinosita, K., Jr \& Ikegami, A. (1988). Structure and function of bacteriorhodopsin. Advan. Biophys. 24, 123-175.

80. Pebay-Peroula, E., Rummel, G., Rosenbusch, J. P. \& Landau, E. M. (1997). X-ray structure of bacteriorhodopsin at $2.5 \AA$ resolution from microcrystals grown in lipidic cubic phases. Science, 277, $1676-1681$.

81. Kabsch, W. (1976). A solution for the best rotation to relate two sets of vectors. Acta Crystallog. sect. A, 32, 922-923.

82. Brooks, B. R., Bruccoleri, R. E., Olafson, B. D., States, D. J., Swaminathan, S. \& Karplus, M. (1983). CHARMM: a program for macromolecular energy, minimization, and dynamics calculation. J. Comput. Chem. 4, 187-217.

83. Brünger, A. T. \& Karplus, M. (1988). Polar hydrogen positions in proteins: empirical energy placement and neutron diffraction comparison. Proteins: Struct. Funct. Genet. 4, 148-156.

84. MacKerell, A. D., Bashford, D., Bellott, M., Dunbrack, R. L., Jr, Evanseck, J. D., Field, M. J. et al. (1998). All-atom empirical potential for molecular modeling and dynamics studies of proteins. J. Phys. Chem. B, 102, 3586-3616.

85. McDonald, I. K. \& Thornton, J. M. (1994). Satisfying hydrogen bonding potential in proteins. J. Mol. Biol. 238, 777-793.

86. Lindauer, K., Bendic, C. \& Suehnel, J. (1996). HBexplore-a new tool for identifying and analyzing hydrogen bonding patterns in biological macromolecules. Comput. Appl. Biosci. 12, 281-289.

87. Foley, J. D. (1982). Fundamentals of Interactive Computer Graphics, Addison-Wesley, Reading, MA.

88. Dijkstra, E. W. (1959). A note on two problems in connexion with graphs. Numer. Math, 1, 269-271.

89. Luecke, H., Schobert, B., Richter, H.-T., Cartailler, J.-P. \& Lanyi, J. K. (1999). Structural changes in bacteriorhodopsin during ion transport at 2 angstrom resolution. Science, 286, 255-260.

90. Luecke, H., Schobert, B., Cartailler, J. P., Richter, H. T., Rosengarth, A., Needleman, R. \& Lanyi, J. K. (2000). Coupling photoisomerization of retinal to directional transport in bacteriorhodopsin. J. Mol. Biol. 300, 1237-1255.

91. Klapper, I., Hagstrom, R., Fine, R., Sharp, K. \& Honig, B. (1986). Focusing of electric fields in the active site of $\mathrm{Cu}-\mathrm{Zn}$ superoxide dismutase: effects of ionic strength and amino-acid modification. Proteins: Struct. Funct. Genet. 1, 47-59.

92. Bashford, D. (1997). An object-oriented programming suite for electrostatic effects in biological molecules. In Scientific Computing in Object-Oriented Parallel Environments (Ishikawa, Y., Oldehoeft, R. R., Reynders, J. V. W. \& Tholburn, M., eds), vol. 1343, pp. 233-240, Springer, Berlin.

93. Vosko, S. H., Wilk, L. \& Nusair, M. (1980). Accurate 
spin-dependent electron liquid correlation energies for local spin density calculations: a critical analysis. Can. J. Phys. 58, 1200-1211.

94. Perdew, J. \& Wang, Y. (1992). Accurate and simple analytic representation of the electron-gas correlation energy. Phys. Rev. ser. B, 45, 13244-13249.

95. te Velde, G., Bickelhaupt, F. M., Baerends, E. J., Guerra, C. F., van Gisbergen, S. J. A., Snijders, J. G. \& Ziegler, T. (2001). Chemistry with ADF. J. Comput. Chem. 22, 931-967.

96. Breneman, C. N. \& Wiberg, K. B. (1990). Determining atom-centered monopoles from molecular electrostatic potentials. Need for high sampling density in formamide conformational analysis. J. Comput. Chem. 11, 361-373.

97. Chen, J. L., Noodleman, L., Case, D. \& Bashford, D. (1994). Incorporating solvation effects into density functional electronic structure calculations. J. Phys. Chem. 98, 11059-11068.

98. Baudry, J., Crouzy, S., Roux, B. \& Smith, J. C. (1999). Simulation analysis of the retinal conformational equilibrium in dark-adapted bacteriorhodopsin. Biophys. J. 76, 1909-1917.

99. Bashford, D., Case, D. A., Dalvit, C., Tennant, L. \&
Wright, P. E. (1993). Electrostatic calculations of side-chain $\mathrm{pKa}$ values in myoglobin and comparison with NMR data for histidines. Biochemistry, 32, 8045-8056.

100. Rabenstein, B., Ullmann, G. M. \& Knapp, E. W. (1998). Energetics of electrontransfer and protonation reactions of the quinones in the photosynthetic reaction center of Rhodopseudomonas viridis. Biochemistry, 37, 2488-2495.

101. Rabenstein, B. \& Knapp, E. W. (2001). Calculated $\mathrm{pH}$-dependent population and protonation of carbon-monoxy-myoglobin conformers. Biophys. J. 80, 1141-1150.

102. Rabenstein, B., Ullmann, G. M. \& Knapp, E. W. (1998). Calculation of protonation patterns in proteins with structural relaxation and molecular ensembles-application to the photosynthetic reaction center. Eur. Biophys. J. 27, 626-637.

103. Wessel, P. \& Smith, W. H. F. (1998). New, improved version of the Generic Mapping Tools released. EOS Trans. AGU, 79, 579.

104. Connolly, M. L. (1983). Analytical molecular surface calculation. J. Appl. Crystallog. 16, 548-558.

Edited by B. Honig

(Received 30 July 2003; received in revised form 22 December 2003; accepted 22 March 2004) 